\title{
Heat Warnings and Avoidance Behavior: Evidence from a Bike-Sharing System
}

\author{
Mariano J. Rabassa* \\ Pontificia Universidad Católica Argentina \\ Buenos Aires, Argentina \\ Mariana Conte Grand \\ Universidad del CEMA \\ Buenos Aires, Argentina \\ Christian M. García-Witulski \\ Pontificia Universidad Católica Argentina \\ Buenos Aires, Argentina
}

\begin{abstract}
Governments throughout the globe usually implement early warning systems to prevent health-related costs from exposure to extreme heat. In a warming world, this type of information-provision approach is believed to be an effective way to deal with this natural hazard, even when there is little evidence of its influence on individuals' behavior. Using detailed information from 1 million trips recorded by a bike-sharing system in Buenos Aires, Argentina, this paper investigates the direct behavioral impact of heat warnings on cycling trips. The results show substantial avoidance behavior for female cyclists and older users: the number of trips for those groups decreases following a heat warning. Alternative specifications for temperature and falsification tests suggest that the findings are robust. As in other studies, this paper also shows that the impact is diluted as time under alert increases.
\end{abstract}

Keywords avoidance behavior, climate change, disaster warning system, environmental health, heatwaves

JEL Classification I12, I18, Q54

*The authors are grateful to seminar participants at UCA, UCEMA, the RIDGE Workshop on Environmental Economics, and to two anonymous reviewers for their constructive comments. The authors declare that they have no conflict of interest. Contact information: Mariano Rabassa, mariano_rabassa@uca.edu .ar, 1600 Av. Alicia Moreau de Justo, Edificio San José, Pontificia Universidad Católica Argentina, C1107AAZ, Buenos Aires, Argentina. Mariana Conte Grand mcg@ucema.edu.ar Christian García-Witulski christian_garcia@uca.edu.ar 


\section{Introduction}

As a result of human-caused climate change, the global mean surface air temperature has been steadily rising since pre-industrial times. This has led to a worldwide increase in the frequency, intensity and duration of heat events, which are predicted to increase in the foreseeable future. According to the Intergovernmental Panel on Climate Change 5th Assessment Report 'it is very likely that heatwaves will occur more often and last longer' (IPCC (2014)).

Heatwaves are amongst the most common and dangerous of natural hazards. It is well documented that exposure to extreme heat has a detrimental effect on human health, resulting in increased mortality and morbidity across a variety of geographical locations (for a recent survey see Campbell et al. $(2018)$ ). In fact, the death toll from a heat event could be counted in the tens of thousands. For example, a peer-review analysis places the 2003 European heatwave death toll at more than 70,000 people (Robine et al. (2008)). In the United States, heat and heat-induced droughts ranked as the number one cause of death among total hazard mortality between 1970 and 2004 (Borden and Cutter (2008)). Heat stress also derives in productivity losses due to absenteeism and less productive presenteeism (Zander et al. (2015)).

Even if the costs of arising from heat events appear to be high, they may indeed be understated since some of the impacts might be compensated by avoidance behavior, mainly through time reallocations (Graff Zivin and Neidell (2014)). Hence, in order to minimize health risks and productivity losses by fostering individuals' averting behaviors, governments around the globe have developed and implemented information dissemination policies. Thus, there are policies to inform on several safety aspects: water quality; food nutritional and hazardous contents; smoking hazards; air quality; adequate temperature to develop outdoor activities, etc. As such, information provision plays an important role in health and environmental regulation. Within the category of information released to the public, there is a particular one we deal with: that of the alerts, advisories or warnings.

The economic rationale behind that type of reaction is that utility-maximizing individuals are subject to their income and time constraints while at the same time they can influence their own health (Harrington and Portney (1987)). More specifically, their health production function depends on personal exposure to health risks, which is compensated by averting and mitigation behaviors. The former are preventive actions that take place before any health impact in order to escape the potential consequences of the informed risk, while the latter appear as a remedy after an exposure has led to a negative health outcome. Our paper deals with avoidance, rather than with mitigation behaviors. Avoidance behaviors include changing activities or buying certain goods to reduce exposure to an environmental risk. Here we focus on the former. ${ }^{1}$

Not all public information disclosure is persuasive; it depends on how the communication is implemented (in terms of content and dissemination of the message) and how it is perceived by the individuals (how willing they are to change their behavior in order to avoid the informed risk). As we show below, one aspect addressed in the literature is that information affects different social groups in different ways.

1 Liu et al. (2018) can serve as an illustration of buying goods to reduce exposure. The authors find for major Chinese cities, that haze alerts issued when the air is "severely polluted" induce a doubling of anti-PM2.5 masks and air filters searches on online mobile devices. 
Not only is it a matter of how different people interpret an alert but also how, as it is often the case, warnings are designed for specific groups. ${ }^{2}$

This article studies heatwave warnings as a policy tool and explores to what extent these warnings induce avoiding behaviors among cyclists in Buenos Aires, Argentina. The data comes from EcoBici, a bikesharing system run by the government of the City of Buenos Aires. EcoBici provides a detailed record for each trip, including the exact time of the day and station in which the trip began and ended. Our results show that heat alerts do affect cycling behavior by reducing the daily count of trips, especially among older people and females. In particular, we find that an alert reduces the number of trips by 20 percent for users older than 60 years of age. Also, we find that females of all ages are very responsive to heat alerts. An alert induces a reduction in both younger and older women's daily trips of 16.6 percent and 25.1 percent, respectively.

To the best of our knowledge, this is the first article that presents evidence by age and gender of policyinduced avoiding behavior in the population, and that is the paper's main contribution. Our findings are important because they imply that heat advisories are an effective policy to protect the population from heatwaves, especially those more vulnerable to heat exposure as senior citizens. A second contribution of this article is to show that the policy also produces some significant unintended spillover effects on women despite not being considered especially vulnerable or at-risk. Also, it is the first paper on averting behavior effects due to health or environmental alerts in a developing country.

The article is organized as follows: Section 2 reviews the related literature. Section 3 explains the empirical strategy. Section 4 describes heatwave and weather data, as well as information on bike use. Section 5 shows the results and Section 6 presents the conclusions.

\section{$2 \quad$ Related Literature}

\subsection{Alerts and avoiding behavior}

There are two lines of research in the literature that capture the impacts of warnings: studies that focus directly on behavior and those that indirectly measure behavior consequences. The latter include alert impacts on morbidity or mortality and their associated costs, or on pollution levels (see Neidell (2004) for the impact of smog alerts on asthma hospitalizations in California; Neidell (2009) specifically for asthma-related children hospitalizations when air quality alerts are issued in Southern California; Moretti and Neidell (2011) for the impact of ozone warnings on hospitalizations in the Los Angeles area; Ward (2015) for fine particulate matter level alerts and hospitalizations in Ontario, Canada, among others). ${ }^{3}$ Mortality and morbidity is a consequence of changes in individuals' behavior when an alert is issued, it does not capture in a direct way the change in people's conduct when they face a warning.

\footnotetext{
${ }^{2}$ For example, Shimshack et al. (2007) show that there was a reduction in the purchase of canned fish in the U.S. after the Food Administration issued an advice targeting pregnant women and children in 2001 about eating fish and shellfish. Nevertheless, they find that it did not have significant impact among less educated people with no newspaper readership even if they belonged to the group at risk, and that people who had not been targeted also forwent the (healthy) eating of fish in response to an alert that was not meant for them.

${ }^{3}$ In that same line, but for developing countries, Mullins and Bharadwaj (2015) find that for Santiago, Chile, the announcement of air pollution "environmental episodes" (bundled with other measures that accompany them, such as restrictions on certain types of emitters) decrease the levels of particulate matter by $20 \%$ and diminishes mortality among the elderly.
} 
On the contrary, there are fewer studies about impacts on direct behavior, which is the line of research directly related to our work. In general, that literature tries to estimate the effect of health and environmental alerts based on stated or on revealed preference data. Our work focuses on revealed and not survey-based behavior. ${ }^{4}$ In our line of research, quantified impacts are related to outdoor activities (park visiting), transportation (traffic volumes, cycling) and consumption (contaminated fish or water). Since cycling is an outdoor activity and also a mode of transportation, we focus here on the first two types of impacts. The warnings most usually studied in those categories are the air quality advisories.

Alert-induced averting behavior in response to air pollution has been quantified for several cities in the United States (Atlanta, Chicago, Los Angeles, San Francisco) and for Sydney in Australia. The avoiding behaviors that have been measured differ among studies, which is an expected result since how information is gathered and released, individuals' awareness, recreation and transportation alternatives, and the overall context differ substantially across the different cities and countries. Articles on revealed avoidance behavior generally study variations in the size of the impact for different types of users (i.e. their socioeconomic characteristics as well as their expertise), routes (if it is a recreational or utilitarian/commuter trip), time of the day, day of the week, holidays, etc.

For recreation impacts, Graff Zivin and Neidell (2009) show that, when an (ozone) smog alert is issued, daily attendance to the Los Angeles Zoo and the Griffith Park Observatory falls. ${ }^{5}$ The authors finds a smaller magnitude for the Observatory averting effect (5\% versus $15 \%$ for the Zoo), which is consistent with the fact that the visits to the Observatory include night hours (i.e., time during which the ozone levels decrease, so less avoidance behavior can be expected). ${ }^{6}$ Also for outdoor averting behavior linked to air pollution warnings, Noonan (2011) builds a database on the use of the Piedmont Park in Atlanta by accounting for passersby. He concludes that ozone alerts do not affect park usage, except for the elderly. The proportion of that segment of users decreases from $2 \%$ of all visitors to $1.98 \%$ (this means a significant decrease of 5\%). Using a different technique (regression discontinuity), Noonan (2014) confirms the lack of impact for all users, the averting behavior for the elderly, and finds a statistically significant effect for joggers (that latter impact was present in Noonan (2011) but lacked significance).

For averting behavior in transportation, Cutter and Neidell (2009) combine data on (ozone) "Spare the Air" advisories in the San Francisco Bay Area with highway traffic volumes and public transit ridership and find that the alerts reduce total daily traffic by about $2.5-3.5 \%$, but there are no significant effects on daily public transit use except for peak commuting hours. In a similar vein, Welch et al. (2005) study how ozone action day advisories impact on train ridership for the city of Chicago and find that although the overall effect for the day is not significant, nonetheless there are changes in hourly ridership (what the authors call scheduling effects: for example, people who usually travel in the afternoon hours shift their usual travel time to avoid peak pollution levels, and so travel later earlier in the morning or later

\footnotetext{
${ }^{4}$ There are some articles on the effect of warnings on time use, based on recall information from surveys such as the American Time Use Survey (ATUS). For example, Noonan (2011) studies the impact of ozone alerts in 300 cities in the U.S. and concludes that the impact on sports and recreation time spent outdoors is not significant, even if there is a reduction in day time traveling on the days of the alert. With the same data, but with different variables, Sexton Ward and Beatty (2016) study air quality alerts in U.S. jurisdictions with more than 350,000 inhabitants and conclude that on average individuals engage in averting behaviors on alert days by reducing the time they spend in vigorous outdoor activities by $18 \%$ (approximately 21 minutes), and that the result is driven by the avoidance behavior of the elderly (younger individuals -under than 65 years old- do not significantly react to the alert).

5 Graff Zivin and Neidell (2009) is similar to Neidell (2009) but considers the impact of consecutive alert days.

6 Neidell (2005), study the impact of smog alerts on visits to the Los Angeles County Arboretum, but finds no statistically significant effect.
} 
in the day: this explains why trains' ridership decreases between 12 to 4 pm, and increases from 9 to 11 am and from 5 to $9 \mathrm{pm}) .^{7,8}$

Among the literature that focuses specifically on cycling, Saberian (2014) investigates the extent to which ozone level alerts impact bike trips in Sydney, Australia. The author argues that cycling is a better measure of outdoor exposure averting behavior because cycling is an activity that takes place fully outdoors, while the same cannot be said for Zoo visits or for the Observatory visitations considered in Graff Zivin and Neidell (2009). ${ }^{9}$ Saberian (2014) finds that a one-time ozone alert reduces cycling trips by $25 \%$. The author shows that the effect of warnings on the number of cyclists is higher on weekends than on weekdays (60\% and 12\%, respectively), whereas cycling trips decrease $18 \%$ for commuter bike routes and $24 \%$ for leisure ones. This indicates that the averting behavior is stronger for leisure activities on weekends. These results are robust to nonlinear specifications of the model.

The literature on averting behavior also sheds light on other specific issues such as the intertemporal impact or the unintended consequences of changes in behavior. ${ }^{10}$ A growing body of evidence suggests that the impact of alerts is diluted as time under alerts passes. This result is attributed to the fact that the costs of intertemporally substituting actions to overcome the environmental risks increase over time. In that line, Graff Zivin and Neidell (2009) show, using recreational visits to the Los Angeles Zoo and the Griffith Park Observatory from 1989 to 1997, that when an (ozone) smog alert is issued for consecutive days, daily attendance decreases between $8 \%$ and $15 \%$ the first day, at most $5 \%$ the second day, and $0 \%$ the third day, and is not significant in the last two cases. For cycling, Saberian (2014) shows that when an alert is issued over two consecutive days, on the second day the impact decreases substantially and loses its significance. Saberian et al. (2017), using the same data and a slightly different empirical strategy as Saberian (2014), find a 35\% reduction in strenuous outdoor activities when an air pollution alert is issued in Sydney, and that impacts drop to $5 \%$ when a second day alert is issued.

To summarize, we have discussed the literature on health-related environmental warnings, and to our knowledge, Saberian (2014) and Saberian et al. (2017) are the only articles that study averting behavior in cycling and they do so in relation to air quality and not heat alerts. We were not able to find any article that measures avoidance behavior in relation to heatwave alerts, even when it is evident that quantifying its potential would be a key outcome for climate change adaptation policies.

\subsection{Weather conditions and cycling}

There is another more developed field of research which studies the effect of local weather on bike use. In this case, weather conditions are usually captured by temperature, both real and perceived, rain, humidity and, less often, the presence of wind, snow, fog, hours of sunshine, cloud coverage, and even

\footnotetext{
${ }^{7}$ Using Ozone Action Days advisories and aggregate traffic volumes for Atlanta, Cummings and Walker (2000) obtained a similar, fairly small and not statistically significant result.

${ }^{8}$ The literature also acknowledges that alerts may have the intended effect or may imply overreaction or undesirable spillovers. For example, Tribby et al. (2013) find for the Salt Lake and Davis counties that in response to the air pollution alert traffic levels decrease in the city center but increase in the metropolitan area. In a similar direction, Jie-Sheng et al (2018) for Beijing (China) show that air pollution advisories can also induce averting behavior in such a way that pollution in fact increases: when pollution is high, people tend to stay indoors and in doing so augment electricity consumption, increasing power stations emissions in such a way that the air quality becomes even worse.

${ }^{9}$ On the contrary, a lesser effect can be expected when considering cycling as opposed to recreational visits because it is likely that cycling may not be optional (some people use bicycles to go to work).

${ }^{10}$ Another technical issue in this literature is the endogeneity problem that we discuss further in the methodological section.
} 
thunderstorms. There are several papers on this topic for various cities in the world, some of which are based on surveys and some on actual behavior. We focus on the latter type of articles. The geographical coverage for that line of research includes Europe, Australia, and North America.

Some of these papers capture the extent to which weather variables explain bike demand in general. For example, Brandenburg et al. (2007) finds, for an area close to Vienna, that the correlation between temperature and precipitations and bike use is strong ( $R^{2}$ is between 0.7 and 0.8). Similarly, Thomas et al. (2013) show for two cities in the Netherlands, that about $80 \%$ of daily fluctuations in cycling demand are explained by daily weather conditions.

Other authors focus more on the impact of each of the weather conditions separately rather than the aggregate effect. Overwhelmingly, precipitations (contemporaneous or lagged) and humidity, when significant, have a negative impact on bike use. However, the temperature effects differ depending on the temperature level (i.e., temperature has a non linear effect on cycling) and usual local conditions (i.e., if the local weather is generally cold or mild and what the range of temperature variation is).

Miranda-Moreno and Nosal (2011) show for Montreal, Canada, that bicycle volumes in a given hour were significantly affected by rainy weather conditions in the same hour and in the previous 3 hours, and that when the temperature increased, bike ridership also increased; however, temperature had a negative effect when it was higher than a certain threshold (that result is confirmed for several Canadian cities in Nosal and Miranda-Moreno (2014)). ${ }^{11}$ El-Assi et al. (2017) also find, in the case of Toronto, different reactions to temperature depending on its level: the higher positive effect occurs for warm temperatures (between 20 and 30 degrees Celsius) whereas hot weather (more than 30 degrees) induces less cycling. Corcoran et al. (2014) focus on a bike-sharing program in Brisbane, Australia, and find that rainfall and higher wind speed have a significant negative impact on the number of trips, whereas temperature has a significant but small impact (and no impact when modeled alone). The author attributes the null or small impact to the fact that there are very small temperature variations in Brisbane.

There are also studies that describe the impact of weather depending on trip purposes. Most commonly, weather determinants tend to be lower for commuting than for recreational cyclists. ${ }^{12}$ It has also been shown that cycling is affected by other factors, such as the surrounding built environment. For example, Gebhart and Noland (2014) show that in Washington D.C., cold temperatures, rain and high humidity reduce both bike use and the duration of trips. And they also capture that bike share stations close to Metro stations are affected by rain more than those which are far from them, an indication that there is a substitution in the mode of transportation when alternatives are more closely available.

Some articles also compare the sensitivity of different age groups and genders to weather conditions. For example, Wang et al. (2018) shows that while humidity and wind speed are negatively correlated to bike ridership in New York City for all cohorts, temperature impacts individuals of different ages in a heterogenous way. An increase in temperature is positively associated to cycling and higher temper-

\footnotetext{
${ }^{11}$ Both references (Nosal and Miranda-Moreno $(2014)$ and Miranda-Moreno and Nosal (2011)) consider non-linearities for both temperature and humidity, but Nosal and Miranda-Moreno (2014) acknowledges that "increases in humidity generally result in decreases in cycle counts, and the non-linear effect was found less consistently than it was for temperature." Another technical feature that is common in this literature is the use of lags for weather conditions. To mention an example, Zhao et al. (2018) model rain and snow with contemporary and a one-period lag.

12 Another result commonly found in this literature is that weekend cycling is more sensitive to weather than cycle counts on weekdays and this is explained by the fact that trips are more leisure oriented on weekends (Thomas et al. (2013)).
} 
atures may deter bike ridership in general, but not for younger millennials (people born between 1995 and 2000). This indicates that older individuals may be generally more sensitive to the weather because they tend to be more concerned about safety and make more trips for recreational and exercise purposes than for commuting (the same argument is referred by Aldred et al. (2016)). However, Saneinejad et al. (2012) find that in the City of Toronto younger bike trip makers (below 25 years old) are more sensitive to colder temperatures than older ones (between 40 and 55).

Previous studies have found that women are not as likely to cycle as men, in particular, in countries with low levels of cycling (Emond et al. (2009); Aldred et al. (2016)). Differences in cycle patterns are generally explained by gender differences in safety concerns as well as housework and care responsibilities (Krizek et al. (2005); Garrard et al. (2008)). Krizek et al. (2005) find, based on surveys for several cities in the US, that women, when cycling, declare stronger preferences for safer routes. They also state that, overall, females use bicycles less often than males because they are more likely to make more escort and encumbered trips with children and goods. ${ }^{13}$ Similarly, Garrard et al. (2008) attributes the lower participation of women in cycling in Australia and the U.S. as compared to several western European countries to the fact that women are more risk averse and so value negatively that in the cycling infrastructure in these English speaking countries bikes are less separated from motor vehicle traffic. ${ }^{14}$ The same authors conclude that the evidence of females cycling shorter distances in the city of Melbourne could originate from the fact that women are more likely to live closer to home due to family responsibilities. ${ }^{15}$

For gender differences in the impact of weather on cycling, specifically Saneinejad et al. (2012) shows that the tendency of females to bike in Toronto is more negatively affected by low temperatures than it is for males. In the same line, Shirgaokar and Habib (2018) find for Edmonton (Canada) that all-year round cyclists tend to be men, while women's biking occurs mostly in warm weather (during Summer, Fall, and Spring).

Several articles also introduce different temperature levels as controls. However, to our knowledge, none of them studies the joint effect of temperature and heat alerts. As discussed in Semenza et al. (2008), it is the failure of a sufficiently strong response to extreme weather events that has triggered the development of advisory systems. Therefore, if temperature is controlled for, it may well happen that its effect is not significant per se since hot weather is concretely taken into account by cyclists only when the alert is issued. Hence, the combination of weather conditions and alerts is a territory to investigate. That is, in

\footnotetext{
13 McGuckin and Nakamoto (2005) have similar findings. They study gender differences in all modes of transportation trip chaining (short stops in a trip to or from work) in the US, and find that "From 1995 to 2001 , women made more short stops on the way to or from work than did men to perform household-sustaining activities, such as shopping and family errands, and working women in two-worker families were twice as likely as men to pick up and drop off school-age children at school during their commute. In the same period (1995 to 2001), men added more stops to their commutes for child care and household errands, especially men in families with young children. But a substantial part of the growth in men's trip chaining was to make a short stop for a meal or coffee on the way to work" (page 50). As reported in Dickinson et al. (2003), women surveyed in the UK cite having to look after their children to explain their low use of bicycles for commuting.

${ }^{14}$ With respect to gender difference in risk taking, Garrard et al. (2008) cite Byrnes et al. (1999), which is a review of 150 articles that shows evidence of women being on average more risk averse than men. Other reviews of the literature exist, in particular for gender differences in investment behavior (see for example, Croson and Gneezy (2009) or Charness and Gneezy (2012), who find that in economic experimental contexts women are less likely to buy risky assets than men). However, even if a substantial portion of the literature has concluded that women are more risk averse than men, some authors (for example Nelson (2015)) review works on this topic and show that even if the average risk aversion is higher, there is a large -80\%- overlap when looking not only at the means but at the overall distribution of risk preferences for men and women).

${ }^{15}$ Similarly, Prati $(2018)$ show that the lower the ranking of countries in the European Gender Equality Index, the higher the percentage of women reporting never using bicycles.
} 
part, what is done in this article.

\section{Data}

As mentioned earlier, this paper tests avoidance behavior due to heat warnings by using very detailed data on the number of daily users and time of use from a bike-sharing system in Buenos Aires, Argentina. Cycling data is complemented with information from the city's heat warning system and daily weather conditions. The following subsections discuss the data sources.

\subsection{Bike use data}

The data on bike usage comes from EcoBici, a station-based bicycle-sharing system run by the government of the City of Buenos Aires, which began operating in early 2010. The system was designed for short-distance commute within downtown, but with time and the extension of the bike lane network, the system has expanded to cover most parts of the city.

EcoBici began operating with just 3 stations and 72 bicycles. However, by 2013 these numbers quickly grew to 29 stations, 800 bicycles and 46,167 active users, which made about 1 million trips. The system is still being expanded, and as of 2019, the network has $227 \mathrm{~km}$ (121 ml) of bike lanes completed and 200 stations, and half a million users. The service provides free of charge access to both residents of the city and tourists, for a one hour-period during weekdays, and a two hour-period on Saturdays. After that time, the user has to return the bike to any station, but he is allowed to take another bike if he wishes. First time users are given an identification number that allows the system to track their use. By the end of 2015 the network became fully automated and registered users could access bicycles 24 hours a day with the use of a smart card or by a cell phone application $(\mathrm{GCBA}(2018))$.

As discussed in the introductory section, EcoBici usage allows to measure people exposure to outdoor weather conditions in a more precise way than other type of data used in previous studies on alerts, such as recall information from time use surveys, the counts of attendance to outdoor facilities, or the count of cyclists passing through a bike path. ${ }^{16}$ In contrast, EcoBici provides a detailed record for each trip, including the exact time of the day and station in which the trip began and ended, along with the user identification number. Besides allowing a better measurement of human exposure to outdoor weather conditions, the database also has the advantage of registering the age and gender of each user.

Due to data availability, this paper uses bike trips recorded from December 2010 through August 2014, when service was only available from 8:00 am to 8:00 pm during weekdays and Saturdays (excluding national holidays). Figure 1 reports the total number of trips per day in Panel A, and the average duration of trips in Panel B. Each point represents daily usage computed from trip level data. Available data for a month is shown vertically with hollow circles representing days in which it rained, and filled circles days in which it did not.

\footnotetext{
${ }^{16}$ In Neidell (2009) and Graff Zivin and Neidell (2009), attendance to the Observatory was registered by hand on counts of two turnstiles located at the entrance, while data for the Zoo was tracked by an automated system that could differentiated kids less than 2 year-old, children between 2-12, and individuals older than 62 years of age. In Saberian (2014) and Saberian et al. (2017), data comes from 31 automated counters, that can only distinguish the time and day of the trip).
} 
The average number of daily trips for the sample period is almost 3,000 trips, though the usage increased as people familiarized with the system, and the number of stations, bicycles and bike lanes grew over time. The observed daily usage fluctuations may be attributed to weather conditions, the expansion of the station and bike lane networks, changes in public transport fares and strikes, and protests and demonstrations that produce traffic congestion, among other factors. From Figure 1 Panel A it is clear that weather is a key determinant of the number of trips, since low usage days correlate with rainy days.

In contrast, average daily time use has been remarkably stable over time (see Figure 1 Panel B). Since October 2011 the average trip has taken about 30 minutes, half of the time of the permitted time for each trip. Before that, trips lasted 10 minutes longer on average and the dispersion in their duration was also larger. The observed change in duration may be due to the creation of new stations which allow the possibility of making shorter trips.

The econometric analysis includes the days between October 15th to March 15th, which, as described in the next subsection, corresponds to the time of the year in which excess heat is being monitored by the National Meteorological Service, responsible of emitting heat warnings. Panel A in Table 1 presents descriptive statistics on bike usage for that time period.

Reported statistics on bike usage correspond to daily averages constructed from 1,041,054 recorded trips taken within the time frame. The average number of daily trips was 2,791 trips with a maximum daily number of 6,284 . As mentioned before, days with very low usage correspond to rainy days. Trips have an average duration of about 31.8 minutes, with a maximum recorded average time of 53.8 minutes. ${ }^{17}$ Users older than 60 year of age, make only 3.3 percent of all daily trips, but their average trip duration is higher. These figures are consistent with those reported for other countries (as shown in Aldred et al. (2016), in low cycling countries, such as England, bike use declines with age and falls abruptly after 65 years, whereas in countries where bikes are a very usual mode of transportation, such as Denmark of Germany, the age gradient exists, but "the proportion of trips cycled in older aged groups remains high"). In Buenos Aires, women are less likely to use the bike-sharing system; only 22 percent of the trips were made by a woman. The low participation of women in the number of bike trips with respect to men is compatible with Emond et al. (2009) that state men's total bicycle trips surpass women's of at least a ratio of 2 to 1 in the United States, and with Garrard et al. (2008) who reports that female rate of commuter cycling is less than one third that of male in Australia. In summary, culture and lifestyles in Buenos Aires are similar as those in other big cities in the world, and gender differences in bicycles' use follow an analogous pattern as in other places with low cycling levels.

\subsection{Heat warnings and weather data}

The National Weather Services (NWS) first implemented a heatwave warning system for the city of Buenos Aires during the 2009-10 summertime. As stated above, the main objective of these advisories is to provide the public with early information on health threats related to extreme heat, and to reduce potential health-related costs by fostering individuals' averting behaviors.

The NWS monitors heat stress for the months from October to March, corresponding to summertime in

\footnotetext{
${ }^{17}$ Longer trips were registered at the beginning of the program in which time penalties for exceeding time restrictions (60 minutes) were lax.
} 
the southern hemisphere. There is no universally accepted definition on what is a heat wave. However, many countries have adopted local criteria for issuing heat wave advisories. In the case of Buenos Aires, the thresholds for issuing a warning are defined based on how extreme temperatures (both maximum and minimum) affect local mortality rates (Almeira et al. (2016)). ${ }^{18}$

As it is common with these types of warnings, the system uses colors to characterize extreme heatwave episodes: green, yellow, orange, and red. A yellow alert is triggered after a day with observed maximum temperature above 32 degrees Celsius, an observed minimum temperature above 20 degrees Celsius and a two-days forecast under similar weather conditions. An orange alert is issued after two consecutive days under a yellow alert and similar weather conditions for the next 48 hours. Finally, a red alert is issued only under extreme circumstances. While yellow and orange alerts target vulnerable population (infants, senior citizens, and people with chronic diseases), red alerts target the whole population.

A heatwave warning is usually issued the previous day at $7 \mathrm{pm}$. Information about heatwave alerts is disseminated by all types of media outlets, and more recently through social media. Thus, it is very likely that people in a densely populated urban area, such as Buenos Aires, are informed about a warning being issued, and its potential risk. ${ }^{19}$

Heatwaves are a common feature of summers in the city. Within the surveillance period, approximately 12 percent of the days resulted in a heatwave warning (see Panel B of Table 1); most of them of the yellow type. It is worth mentioning that while the NWS provides access to a list of days under a warning, and their type, it does not provide the forecasts upon which warnings are issued.

Finally, since the decision to ride a bike is affected by weather conditions other than the alert, data on heatwave warnings are complemented with daily maximum and minimum temperatures, relative humidity, and precipitation. Buenos Aires has a temperate climate, which is classified as a humid subtropical climate (denoted Cfa in the Köppen climate classification), but summers are hot and humid. Panel B in Table 1 provides descriptive statistics on daily weather for the sample period. The average daily maximum temperature was 28.6 degrees Celsius, with a record high of 39 degrees. It rained in 28 percent of the days, and humidity was on average 66.9 percent.

\section{Empirical Strategy}

The estimation strategy has two main objectives. The first one consists of estimating the contemporaneous effect of a heat warning on people's exposure to outdoor weather, using data from EcoBici. For this, the following specification was chosen:

\footnotetext{
${ }^{18}$ Usually extreme heat thresholds are city-specific, since they may differ due to the underline vulnerabilities of the population to extreme heat, such as biomedical and socio-economic characteristics, demographic structure, housing characteristics, among other factors.

${ }^{19}$ Both the NWS and the Government of the City of Buenos Aires have several mechanisms of information dissemination in place. They include not only news in the media, but also public officials posted across the city explaining what is a heat wave and what should be done when a warning is issued. We are confident that all those mechanisms inform most citizens, and so our results are not biased.
} 


$$
\begin{aligned}
\log \left(Y_{d}\right)=\beta_{1} \text { alert }_{d}+\gamma_{1} \text { temp } \max _{d}+\gamma_{2}{\text { temp } \max _{d}^{2}+\alpha_{1} \text { rainfall }_{d}+} \\
\alpha_{2} \text { rainfall }_{d-1}+\omega \text { humidity }_{d}+\mu_{\text {dow }}+\varphi_{m}+\delta_{y m}+\epsilon_{d m y}
\end{aligned}
$$

where $Y_{d}$ corresponds either to the total count of daily trips or their average duration. Because of the non-normal and asymmetric distribution of the dependent variables, their natural logarithm is used instead, since it is an accepted way to approximate almost normal distribution. The variable of interest is alert $_{d}$, a dummy variable which takes the value of one when a heat alert is triggered on day $d$. Since the alert is very much correlated with meteorological conditions, we control for maximum daily temperature, rainfall and relative humidity. To separate the effect of an alert from that of daily temperature, equation 1 includes both linear and quadratic terms for daily maximum temperature. ${ }^{20}$ The variable rainfall ${ }_{d}$ is a dummy variable that captures whether it rained anytime during day $d$, and humidity ${ }_{d}$ represents the daily relative humidity.

Other confounding factors may affect the number of daily trips made or their durations. For instance, expansions to the bike lane network or the opening of new bike-sharing stations should increase EcoBici use. Also, changes in public transportation fares, public demonstrations, and traffic congestion will certainly affect people's transportation choices. In order to acknowledge these potential confounders, equation 1 includes a full set of time-fixed-effects: $\mu_{d o w}, \varphi_{m}$ and $\delta_{y m}$, which capture the day of week-, month-, and year-month fixed-effects, respectively. Finally, $\epsilon_{d m y}$ is an error term.

The coefficient of interest is $\beta_{1}$, which captures differences between the average daily trip counts or their durations, between days without and with a heat warning. The coefficient is expected to be negative, which would indicate that individuals reduce their outdoor exposure in response to the alert. Since older adults are much more affected by summer heat, the estimated $\beta_{1}$ might be more sensitive in vulnerable age groups, and even between males and females. Therefore, the above equation is also estimated by individual's age group (i.e. $<60$ and $\geq 60$ years of age) and by gender.

As mentioned before, existing studies have reported that the contemporaneous effect of (air pollution) alerts changes when there are two or more consecutive days of alerts (Graff Zivin and Neidell (2009), and Saberian et al. (2017)). This result is attributed to the fact that the costs of intertemporally substituting actions to overcome the environmental risks increase through time. Thus, the second objective is to estimate the effect of alert $_{d}$ conditional to alert ${ }_{d-1}$ through the following specification:

$$
\begin{array}{r}
\log \left(Y_{d}\right)=\beta_{1} \text { alert }_{d}+\beta_{2} \text { alert }_{d-1}+\beta_{12} \text { alert }_{d} * \text { alert }_{d-1}+\gamma_{1} \text { temp } \max _{d}+\gamma_{2} \text { temp } \max _{d}^{2}+ \\
\alpha_{1} \text { rainfall }_{d}+\alpha_{2} \text { rainfall }_{d-1}+\omega \text { humidity }_{d}+\mu_{d o w}+\varphi_{m}+\delta_{y m}+\epsilon_{d m y}
\end{array}
$$

In this way, if alerts are issued on two consecutive days, we can estimate $E\left[\log \left(Y_{d}\right) \mid \operatorname{alert}_{d}=1\right.$, alert $_{d-1}=$ 1] $-E\left[\log \left(Y_{d}\right) \mid\right.$ alert $_{d}=0$, alert $\left._{d-1}=1\right]$ through $\beta_{1}+\beta_{12}$, which identifies the additional effect of the alert in day $d$ if in the previous day $d-1$, and alert was also issued. Further, if people respond to two

\footnotetext{
20 Graff Zivin and Neidell (2009) and Saberian et al. (2017) also control for the non-linear effect of temperature on behavior using the same quadratic function. However, in order to assess the robustness of the estimated effect of the alert to other functional forms, the next section presents the results with splines for maximum daily temperature.
} 
consecutive warning days, we can estimate the cumulative dynamic effect by summing the coefficients on the contemporaneous and lagged alert variable, i.e. $\beta_{1}+\beta_{2}+\beta_{12}$.

The validity of the empirical exercise rests on the assumption that the estimation of equations 1 and 2 will produce unbiased estimates of $\beta$ s coefficients, i.e. the contemporaneous and lagged coefficients of the heat warnings, after controlling for outdoor weather conditions and other confounders. However, empirical studies on the effectiveness of air pollution alerts, have pointed out the potential endogeneity of pollution levels. The reasoning behind this argument is that an alert on day $d$ is usually issued early on the same day or sometime during $d-1$. Therefore, people have enough time to respond to the alert, implying less exposure, and less exposure can mean a change to more polluting transportation modes or increases in electricity consumption, both of which may induce more air pollution on day $d .{ }^{21}$

The issue of endogeneity is far less problematic in the context of this study than in those studies dealing with air pollution warnings. Firstly, changes in behavior triggered by heat warnings, that might affect pollution levels, will not have any impact on outdoor weather conditions. In this sense, maximum daily temperatures and precipitation do not depend on the warnings, as pollution levels do. Secondly, it is critical to identify the effect of an alert controlling for outdoor weather conditions, particularly maximum daily temperature. Even though daily the observed maximum temperature is a predictor of a heat alert, it is not a perfect predictor. Warnings are produced using past observed weather realizations and 48-hour weather forecasts, which might not result as expected. Therefore, days with observationally equivalent weather conditions, on which we assume people based their cycling decisions, might or might not have been days under a heat alert. The next section reports Ordinary Least Squares estimates. ${ }^{22}$

\section{Results}

Regression results from equation 1 are presented in Table 2 and Table 3 Estimated coefficients from equation 2 are displayed in Table 4 Finally, robustness checks are reported in Tables 5 to 7 . In all cases, an observation corresponds to a weekday between October 15th to March 15th.

\subsection{Evidence of direct avoidance behavior}

Panel A in Table 2 presents the estimated coefficients for equation 1 when the dependent variable is the logarithm of the total number of daily trips. Column (1) shows that a warning has no significant effect on users younger than 60 years of age, but it has a negative and significant impact, at a 99 percent confidence level, on users older than 60 years of age (Column (2)). ${ }^{23}$ In particular, for the latter age

${ }^{21}$ To overcome the potential endogeneity, studies have relied on different identification strategies. For instance, Graff Zivin and Neidell (2009) and Noonan (2014) applied a regression discontinuity approach to identify the impact of air quality alerts. The identification comes from observing days with similar levels of air quality around the threshold in which a warning is issued. Using a different approach to deal with the endogeneity, Saberian et al. (2017) apply instrumental variables techniques to estimate the impact of air quality warnings on cycling behavior in Sidney, Australia. Similarly, Moretti and Neidell (2011) use daily boat arrivals and departures to the ports of Los Angeles as an instrumental variable for ozone levels.

${ }^{22}$ Some articles capture the impact of warnings using policy evaluation techniques (specifically, regression discontinuity). To apply a regression discontinuity design, the alert must be issued based on a continuous index that has a clearly defined cutoff score. However, contrary to Cutter and Neidell (2009), Neidell (2010), Graff Zivin and Neidell (2009) and Noonan (2014), who study the consequence of air quality alerts based on an air quality continuous variable such as ozone levels, heat warnings in Buenos Aires are based on temperature forecasts over several days, and not actual daily temperature, which is the continuous variable that is available for this study.

${ }^{23}$ Results do not change much is we use a different age threshold (59 or 61 year of age), and the estimated coefficients' significance across all specifications remains as those reported in Panel A in Table 2 
group, an alert reduces the contemporaneous number of trips made using EcoBici by approximately 20 percent. The significance of $\beta_{1}$ for the elder cyclists seems to indicate that warnings only affect the behavior of the population facing higher risks.

In Columns (3) to (6) the sample is divided by gender and age. Both male and female cyclists older than 60 years of age respond to an alert, but females display a larger response than males, 25.1 percent (Column (6)) versus 18.2 percent (Column (4)). However, this last result has to be taken with caution given that fewer trips are made by female users older than 60 years of age, at least compared to those made by their male counterparts. Interestingly, females younger than 60 years of age also reduce their biking trips after a heat alert is issued (Column (5)). The estimated behavioral response for them is 16.6 percent, very similar in magnitude to that for older males.

The impact of a heat alert on trips' duration is showed in Panel B of Table 2 In this case the dependent variable is the log of daily mean trip durations, measured in minutes. Results from the first five specifications suggest no impact of an alert on the average trip duration, i.e. conditional on making a trip in a day in which an alert was issued, those trips take the same amount of time. Only in the last specification, i.e. for older women, a heat alert has a negative effect on the amount of minutes of cycling, however, it is only significant at a 90 percent confidence level. This results suggests that older women use EcoBici to make more recreational type of trips, which could be shortened under riskier outdoor conditions. ${ }^{24}$

Regarding the control variables, both panels of Table 2 show that weather conditions clearly affect EcoBici demand. Having rained greatly reduces bike rides in the same day throughout all specifications reported in Panel A, but the effect is less evident for Panel B. The estimated impact for $\alpha_{1}$ reported in Panel A, ranges from -20.7 percent to -35.8 percent. The effect is greater for older users of both sexes, and for female users of all ages. If rainy conditions were registered the day before, it also reduces EcoBici trips in some specification. As expected, humidity also affects cycling behavior since each percentage point rise in relative humidity reduces bike rides by approximately 1 to 2 percent. Maximum daily temperature has a clear quadratic effect on bike demand, at least in Panel A. The number of trips increase as the daily maximum temperature rises, but a certain temperature level, the number of trips start to decrease. Finally, the overall goodness of fit in models reported in Table 2 are high, and are in line with the literature that relates weather conditions and cycling (see for example Thomas et al. (2013)). For Panel A, the included variables explain between 78 to 92 percent of the variation in daily trips, while for Panel B, they explain between 58 to 84 percent of the variation in daily average time use.

Table 3 reports the impact of a heat warning by commuting time. ${ }^{25}$ Demand for a bike-sharing system is relatively flexible when compared to the one for own bikes. For example, a person that uses her own bike to commute to work, when she rides it to her job, will very likely ride back home after work (bicycles' secure overnight parking options are generally not available). In that case, the impact of an alert should not be very different between the morning and afternoon commuting hours. In contrast, EcoBici allows

\footnotetext{
${ }^{24}$ Our data does not specify if the trip is of the commuting or the recreational type. Our result can be explained by the fact that trips are more of the commuting type, and so, if going to a specific place, the trip cannot change in terms of the path (and so the duration) since trips must begin and end in an EcoBici station. And, in terms of the finding for older women, it may occur that that segment of people does more recreational type trips and so would shorten their duration if a heat alert is issued. Even though those possibilities might explain our results, it is not feasible to test them with the available data.

${ }^{25}$ Given the non-significant effect of heat warnings on time use, Tables 3 to 5 only report versions of equations 1 and 2 when the dependent variable is the log of daily number of trips.
} 
people to chose between alternative transportation modes at different times of the day. Thus, under an alert it is still possible that people would bike to work during the morning commute hours, when the temperature is not very high, and the alert is not so relevant, but that they choose not to be exposed to the outdoor weather during the afternoon commute, when the risk is higher (in Buenos Aires, the temperature usually peaks around 3 to $4 \mathrm{pm}$ in summertime).

All specifications in Table 3 include the same controls as those included in the previous table. As expected, an alert does not affect the demand for EcoBici during the morning hours (between 8am to 10am) compared to a similar day without an alert being issued (Columns (1) and (2)). In contrast, Column (4) shows that, during the afternoon commute (4pm to $6 \mathrm{pm}$ ) when daily temperature usually reaches its maximum, the number of trips for older than 60 years of age users decreases by 21.9 percent (statistically significant at a 99 percent confidence level). The coefficient is similar in magnitude to the one reported in Column (2) of Panel A in Table 3 That is, the overall effect of a heat alert on daily trips reported in the previous table is mainly explained by avoidance behavior during the afternoon hours when risks due to outdoor physical activities are higher.

An interesting finding is that having rained the previous day only reduces ridership during the morning, particularly for older users. We believe this might be due to the presence of remaining puddles of rainwater along bike-lanes the morning after the rain. Older users may feel more aversion to confronting the risk associated to that situation and so that may be the reason they are more sensitive to that background condition.

\subsection{Intertemporal allocation of time}

Table 4 presents the results of estimating equation 2, i.e. the effect of two consecutive days under a heat warning. As explained before, if alerts are issued on two successive days, it is possible to esti-

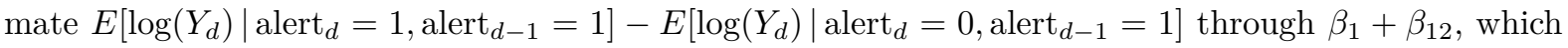
identifies the additional effect of the alert in day $d$ conditional on having an alert in $d-1$, the previous day.

The linear combination of $\beta_{1}+\beta_{12}$ in all six columns is not significant at a 90 percent confidence level (results not reported). That is, statistically, now the contemporaneous effect of a heat warning is not different from zero. Thus, any avoidance behavior displayed during a first-day alert it is not only diluted as time passes, but it largely disappears by the second day. This result is attributed to the fact that the costs of intertemporally substituting actions to overcome the environmental risks increase through time. This "rebound effect" (Graff Zivin and Neidell (2009)) or "alert fatigue" (Saberian et al. (2017)) has important policy implications for the design and dissemination of information during heatwaves. ${ }^{26}$

\subsection{Robustness checks}

This subsection explains and presents the results for three robustness checks: eliminating those days with extreme observed maximum temperatures, modeling maximum temperature by piecewise polyno-

\footnotetext{
${ }^{26}$ Alert fatigue is a well-known phenomenon that occurs when one is exposed to frequent alarms and, as a result, becomes desensitized to them. Desensitization can lead to disregard warnings. Alarm fatigue occurs in many industries (in mining or construction, for example), healthcare (see for example the discussion in Sendelbach and Funk (2013)), etc. It is fair to say that the diluted effect of the reiteration of warnings can not only be attributed to the increasing costs of postponing tasks, but also to some degree of psychological fatigue. However, we believe that because of the different characteristics of the alert, psychological fatigue is not as acute for heat warning as it is in industry or healthcare contexts.
} 
mial functions, and a falsification test.

As mentioned before, it is critical to identify the effect of an alert controlling for outdoor weather conditions, particularly maximum daily temperature. ${ }^{27}$ In this sense, the paper's main goal is to measure the effect of information, in the form of a heat warning, and not the effect of heat per se. Warnings are produced by looking at a three-day window, using past observed weather realizations and 48-hour weather forecasts, which might not result as expected. Thus, even though the observed maximum temperature on day $d$ may be a good predictor of a heat alert in the same day, it is not a perfect predictor. Therefore, days with observationally equivalent weather conditions, on which it is assume that people base their cycling decisions, might or might not have been days under a heat alert.

The first robustness check is to analyze how dependent on extreme heat are the estimated impacts of a heat alert on cycling behavior. Table 5 reports estimated coefficients for equation 1 dropping those days in which the observed maximum temperature exceeded a certain threshold. In particular, days with an observed maximum temperature between $35^{\circ} \mathrm{C}$ and $39^{\circ} \mathrm{C}$ were successively dropped from the sample. ${ }^{28}$ The coefficient on alert $d$ in all six specifications do not change either its sign or its significance level (results can be compared to those reported in Panel A of Table 2). Also, their magnitude does not change much as days are dropped out of the sample. This means that the estimated effect of a heat alert, i.e. the provision of information about a hazard, is not capturing the effect that extreme heat has on cycling demand.

The second robustness check is to control for the effect of daily temperature in a flexible way. For that purpose, a semi-parametric model is estimated in which daily maximum temperature is modeled by a piecewise polynomial function. Results are reported in Table 6 (results can also be compared to those reported in Table 22. The signs of the coefficients on alert ${ }_{d}$ remains the same, but their significance and magnitude do change. For some specification the significance level decrease from 99 percent to 95 percent, and the magnitude of the effect is reduced between 2 and 3 percentage points, but the general conclusions remain unchanged.

A third check is to examine the robustness of the estimated impacts to a placebo intervention. That is, by simulating heat warnings on days that have not received the treatment, the result of fictitious alerts would shed some insight on whether the reported impacts on bike usage are driven by chance or by some other factors. If the number of daily rides decreases under the placebo treatment, then it would not be

\footnotetext{
${ }^{27}$ Potential multicollinearity among the explanatory variables were checked by the variance inflated factor and the correlation matrix of estimated coefficients. These diagnostic tests (results not reported) show weak collinearity among variables.

${ }^{28}$ To assess the potential multicollinearity due to extremely hot days we estimate the probability of a warning as a function of weather conditions and month fixed effects:

$$
\text { alert }_{d}=\alpha_{0}+\beta_{0} \text { alert }_{d-1}+\sum_{i=19}^{39} \gamma_{i} \text { temp } \max _{d i}+\sum_{i=9}^{28} \theta_{i} \text { temp } \min _{d i}+\text { whumidity }_{d}+\lambda_{m}+\epsilon_{d} m
$$

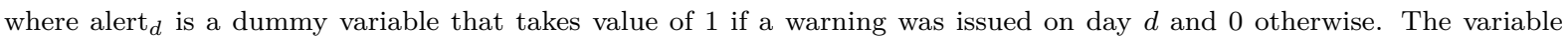

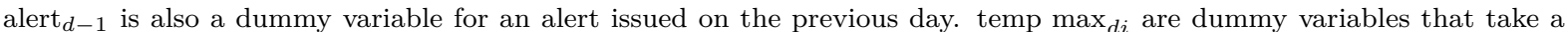
value of 1 if the daily maximum temperature in day $d$ falls within each one-degree Celsius bins (from $19^{\circ}$ Celsius up to $39^{\circ}$ ). This is the most flexible way to account for the effect of maximum temperatures on the probability of an alert being issued. The same interpretation follows for the minimum daily temperature, temp $\min _{d i}$ (for bins between $9^{\circ}$ and up to $28^{\circ}$ Celsius). Humidity is relative humidity on day $d$, and $\lambda_{m}$ are month fixed effects. As in the paper, this regression includes only days between October 15 and March 15. The predicted probability of a warning (not reported here but available upon request) for a day with a maximum temperature of $35^{\circ}$ is about 0.5 (CI $0.35-0.72$ ). In days with maximum temperatures higher than $36^{\circ}$ we cannot ruled out the probability that they become perfect predictors, i.e., the CI for the predicted probabilities does includes one.
} 
possible to attribute the reduction of bike trips to the warning system.

For this purpose, heat alerts were first grouped into different heatwave events using the following day without an alert as a cut-off point, so that each event is constituted by one or a set of alerts triggered on consecutive days. For example, if warnings were triggered between January 1st and January 3rd, these three alerts correspond to a cluster that will be randomized later. Then, a random variable with a uniform distribution between 0 and 1 is generated, so that each number in that range has the same probability of being selected. Based on this, the events are randomly distributed keeping the same distribution as in true alerts.

Subsequently, regressions based on equation 1 were carried out, replacing in our regression model the true alerts for the falsified alerts. In this way, if the results are robust, no statistical significance should be observe between the falsified alerts and the number of daily trips. Table 7 reports the estimated coefficients under the randomized heatwave events. As expected, the reported coefficients, which before were highly significant for the case of the number of trips (Panel A of Table 2), have now no statistical impact on bike demand. This implies that EcoBici demand did not respond to the fictitious treatment. ${ }^{29}$ It is worth mentioning that the estimated coefficients on the control variables do not change their magnitude nor their significance level under the placebo test. Therefore, higher confidence can be attached to the results described in the previous subsections.

\section{Conclusions}

Heatwaves are a natural hazard whose frequency is expected to increase as climate change evolves. Heat stress has important health and labor productivity consequences shown by different studies for several places in the world.

One possible response to this phenomenon comes through information-provision policies which alert the population to potential risks, triggering different forms of avoidance behavior such as reducing the time spent outdoors, increasing the use of cooling devices, wearing light-colored clothes or keeping hydrated. Alerts, which are given when health or environmental indicators exceed some threshold, aim to encourage averting behaviors among individuals to compensate for some of the negative impacts of environmental dangers, thus partly attenuating the social costs linked to them. However, little is known about how effective heat warning systems are in inducing these behaviors.

Despite there being several articles dealing with the impact of weather conditions such as temperature or rain on human activities, and others on how air quality warnings affect the time individuals spend outdoors, this paper is the first to measure how responsive are individuals to heat alerts. It does so with precise data on cycling trips as well as cyclists' characteristics, specifically, gender and age.

The behavioral response to a heat alert is evaluated by looking at how users of a bike-sharing system in Buenos Aires, Argentina, change their trips when a heat warning is issued. This is also new to the existing literature, since it is the first work that assesses the impact of environmental alerts in revealed

\footnotetext{
${ }^{29}$ Results from the falsification test do not differ if applied to models specified by equation 2 . They are available upon request.
} 
avoidance behavior for a city outside the United States or Australia.

The results indicate that heat alerts reduce daily bike trips of senior citizens by $20.2 \%$, whereas the reduction is not statistically significant for younger users. This is in line with results reported in previous studies, given that older people tend to be more sensitive to weather conditions (Wang et al. (2018)) because they are more concerned with safety, and also because cycling for them tends to be more recreational rather than commuting based (and so face lower costs for adapting their behavior).

Another important finding is that females of all ages are very responsive to heat alerts. An alert induces a reduction in both younger and older women's daily trips of $16.6 \%$ and $25.1 \%$, respectively. This is compatible with the existing evidence, which reports that there is a gender gap in transportation usage. This gap is explained by differences in risk aversion and cycling patterns between genders (Garrard et al. (2008)).

Weather conditions have also been proved to affect bike use. Rainy weather, as well as relative humidity, reduces daily trips for both genders and for all ages, and as was the case with the alert, the impact is higher for women and older individuals. If it had rained the day before, only senior citizen trips occurring in the morning are affected; those taking place in the afternoon do not change significantly.

As in the previous literature for air pollution alerts (Graff Zivin and Neidell (2009) and Saberian et al. (2017)), the results suggest that costs associated with performing avoidance behavior increases with time. The estimates of a heat warning on the second day of two consecutive days under an alert is not significant. This indicates that the impact of the alert is diluted as time passes. Thus, individuals simply disregard the second day of heat warning when deciding about their bike use.

All findings are robust, as shown by the results of several robustness checks. The analysis shown in this paper does have, however, some limitations. Firstly, it could be argued that the results provide an upper bound of the true impact since the data comes from a bike-sharing system in which users can desist from cycling when commuting back from work at moments when the alert is more binding, i.e. during the afternoon hours. Secondly, the database does not allow to distinguish commuting from recreational trips. Finally, the study uses data for the capital of Argentina, which is considered a low-cycling city by international standards, but which is similar in this respect to English speaking countries such as the United Kingdom or the U.S. Thus, the findings cannot be automatically extrapolated to other cities in the same country, the same continent or other places in the world. However, our analysis does have clear implications for policy making since it is a first step towards measuring the usefulness of a climate change adaptation policy such as a heat warning system.

\section{References}

Aldred, R., Woodcock, J., and Goodman, A. (2016). Does more cycling mean more diversity in cycling? Transport Reviews, 36(1):28-44.

Almeira, G., Rusticucci, M., and Suaya, M. (2016). Relación entre mortalidad y temperaturas extremas en Buenos Aires y Rosario. Meteorológica, 41(2):65-79. 
Borden, K. A. and Cutter, S. L. (2008). Spatial patterns of natural hazards mortality in the United States. International Journal of Health Geographic, 17(Dec):7-64.

Brandenburg, C., Matzarakis, A., and Arnberger, A. (2007). Weather and cycling - a first approach to the effects of weather conditions on cycling. Meteorological Applications, 14(1):61-67.

Byrnes, J. P., Miller, D. C., and Schafe, W. D. (1999). Gender differences in risk taking: A meta-analysis. Psychological Bulletin, 125(3):367-383.

Campbell, S., Remenyi, T. A., White, C. J., and Johnston, F. H. (2018). Heatwaves and health impact research: A global review. Health and Place, 53:210-218.

Charness, G. and Gneezy, U. (2012). Strong evidence for gender differences in risk taking. Journal of Economic Behavior and Organization, 83(1):50-58.

Corcoran, J., Li, T., Rohde, D., Charles-Edwards, E., and Mateo-Babiano, D. (2014). Spatio-temporal patterns of a public bicycle sharing program: the effect of weather and calendar events. Journal of Transport Geography, 41(C):292-305.

Croson, R. and Gneezy, U. (2009). Gender differences in preferences. Journal of Economic Literature, $47(2): 448-474$.

Cummings, R. and Walker, M. B. (2000). Measuring the effectiveness of voluntary emission reduction programmes. Applied Economics, 32(13):1719-1726.

Cutter, W. B. and Neidell, M. (2009). Voluntary information programs and environmental regulation: Evidence from 'Spare the Air'. Journal of Environmental Economics and Management, 58(3):253-265.

Dickinson, J. E., Kingham, S., Copsey, S., and Pearlmen Hougie, D. J. (2003). Employer travel plans, cycling and gender: will travel plan measures improve the outlook for cycling to work in the UK? Transportation Research Part D, 8(1):53-67.

El-Assi, W., Salah Mahmoud, M., and Nurul Habib, K. (2017). Effects of built environment and weather on bike sharing demand: a station level analysis of commercial bike sharing in Toronto. Transportation, 44(3):589-613.

Emond, C., Tang, W., and Handy, S. (2009). Explaining gender difference in bicycling behavior. Transportation Research Record, 2125(1):16-25.

Garrard, J., Rose, G., and Lo, S. K. (2008). Promoting transportation cycling for women: The role of bicycle infrastructure. Preventive Medicine, 46(1):55-59.

GCBA (2018). Ecobici: La historia de la bici en Buenos Aires [Brochure]. Subsecretaria de Movilidad Sustentable y Segura, Gobierno de la Ciudad de Buenos Aire. Retrieved from: www.buenosaires.gob.ar/ecobici/historia-de-la-bici.

Gebhart, K. and Noland, R. (2014). The impact of weather conditions on bikeshare trips in Washington, DC. Transportation, 41(6):1205-1225.

Graff Zivin, J. and Neidell, M. (2009). Days of haze: Environmental information disclosure and intertemporal avoidance behavior. Journal of Environmental Economics and Management, 58(2):119-128. 
Graff Zivin, J. and Neidell, M. (2014). Temperature and the allocation of time: Implications for climate change. Journal of Labor Economics, 32(1):1-26.

Harrington, W. and Portney, P. R. (1987). Valuing the benefits of health and safety regulation. Journal of Urban Economics, 22(1):101-112.

IPCC (2014). Synthesis Report. Contribution of Working Groups I, II and III to the Fifth Assessment Report of the Intergovernmental Panel on Climate Change. Technical report, Intergovernmental Panel on Climate Change.

Krizek, K., Johnson, P., and Tilahun, N. (2005). Gender differences in bicycling behavior and facility preferences. In Conference Proceedings, volume 35, page 31. Transportation Research Board, Washington, DC.

Liu, T., He, G., and Lau, A. (2018). Avoidance behavior against air pollution: Evidence from online search indices for anti-PM2.5 masks and air filters in Chinese cities. Environmental Economics and Policy Studies, 20(2):325-363.

McGuckin, N. and Nakamoto, Y. (2005). Differences in trip chaining by men and women's issues in transportation. In Conference Proceedings, volume 35, page 31. Transportation Research Board, Washington, DC.

Miranda-Moreno, L. and Nosal, T. (2011). Weather or not to cycle: Temporal trends and impact of weather on cycling in an urban environment. Transportation Research Record, 2247(1):42-52.

Moretti, E. and Neidell, M. (2011). Pollution, health, and avoidance behavior: Evidence form the Ports of Los Angeles. Journal of Human Resources, 46(1):154-175.

Mullins, J. and Bharadwaj, P. (2015). Effects of short-term measures to curb air pollution: Evidence from Santiago, Chile. American Journal of Agricultural Economics, 97(4):1107-1134.

Neidell, M. (2004). Air pollution, health, and socio-economic status: the effect of outdoor air quality on childhood asthma. Journal of Health Economics, 23(6):1209-1236.

Neidell, M. (2005). Information and avoidance behavior: Do people respond to smog alerts? Center for Integrating Statistical and Environmental Science, Technical Repor No. 24, The University of Chicago, March.

Neidell, M. (2009). Information, avoidance behavior, and health the effect of ozone on asthma hospitalizations. Journal of Human Resources, 44(2):450-478.

Neidell, M. (2010). Air quality warnings and outdoor activities: evidence from Southern California using a Regression Discontinuity Design. Journal of Epidemiology and Community Health, 64(10):921-926.

Nelson, J. A. (2015). Are women really more risk-averse than men? A re-analysis of the literature using expanded methods. Journal of Economic Surveys, 29(3):566-585.

Noonan, D. (2011). Smoggy with a chance of altruism: Using air quality forecasts to drive behavioral change. Technical Report AEI Working Paper, American Enterprise Institute.

Noonan, D. (2014). Smoggy with a chance of altruism: The effects of ozone alerts on outdoor recreation and driving in Atlanta. Policy Studies Journal, 42(1):122-145. 
Nosal, T. and Miranda-Moreno, L. (2014). The effect of weather on the use of North American bicycle facilities: a multi-city analysis using automatic counts. Transportation Research Part A: Policy and Practice, 66(1):213-225.

Prati, G. (2018). Gender equality and women's participation in transport cycling. Journal of Transport Geography, 66(January):369-375.

Robine, J.-M., Cheung, S. L. K., Le Roy, S., Van Oyen, H., Griffiths, C., Michel, J.-P., and Herrmann, F. R. (2008). Death toll exceeded 70,000 in europe during the summer of 2003. Comptes Rendus Biologies, 331(2):171-178.

Saberian, S. (2014). Behavioral impacts of air quality alerts: cycling and ozone alerts in Sydney. Retrieved from: www.cireqmontreal.com/wp-content/uploads/2015/ 07/saberian.pdf. Last access April 30, 2019.

Saberian, S., Heyes, A., and Rivers, N. (2017). Alerts work! air quality warnings and cycling. Resource and Energy Economics, 49(1):165-185.

Saneinejad, S., Roorda, M., and Kennedy, C. (2012). Modelling the impact of weather conditions on active transportation travel behaviuor. Transportation Research Part D: Transport and Environment, $17(2): 129-137$.

Semenza, J., Wison, D., Parra, J., Bontempo, B., Hart, M., Sailor, D., and George, L. (2008). Public perception and behavior change in relationship to hot weather and air pollution. Environmental Research, 107(3):401-411.

Sendelbach, S. and Funk, M. (2013). Alert fatigue: a patient safety concern. AANC Advanced Critical Care, 24(4):378-386.

Sexton Ward, A. L. and Beatty, T. K. (2016). Who responds to air quality alerts? Environmental and Resource Economics, 65(2):487-511.

Shimshack, J. P., Ward, M. B., and Beatty, T. K. (2007). Mercury advisories: Information, education, and fish consumption. Journal of Environmental Economics and Management, 53(2):158-179.

Shirgaokar, M. and Habib, K. N. (2018). How does the inclination to bicycle sway the decision to ride in warm and winter seasons? International Journal of Sustainable Transportation, 12(6):397-406.

Thomas, T., Jaarsma, R., and Tutert, B. (2013). Exploring temporal fluctuations of daily cycling demand on Dutch cycle paths: The influence of weather on cycling. Transportation, 40(1):1-22.

Tribby, C. P., Miller, H. J., Song, Y., and Smith, K. R. (2013). Do air quality alerts reduce traffic? an analysis of traffic data from the Salt Lake City metropolitan area, Utah, USA. Transport Policy, $30(\mathrm{C}): 173-185$.

Wang, K., Akar, G., and Chen, Y.-J. (2018). Bike sharing differences among millennials, gen xers, and baby boomers: Lessons learnt from New York CityâĂŹs bike share. Transportation Research Part A: Policy and Practice, 116(C):1-14.

Ward, C. (2015). It's an ill wind: The effect of fine particulate air pollution on respiratory hospitalizations. Canadian Journal of Economics, 48(5):1694-1732. 
Welch, E., Gu, X., and Kramer, L. (2005). The effects of ozone action day public advisories on train ridership in Chicago. Transportation Research Part D: Transport and Environment, 10(6):445-458.

Zander, K. K., Botzen, W. J., Oppermann, E., Kjellstrom, T., and Garnett, S. T. (2015). Heat stress causes substantial labour productivity loss in Australia. Nature Climate Change, 5(July):647-652.

Zhao, J., Wang, J., Xing, Z., Luan, X., and Jiang, Y. (2018). Weather and cycling: Mining big data to have an in-depth understanding of the association of weather variability with cycling on an off-road trail and an on-road bike lane. Transportation Research Part A: Policy and Practice, 111(C):119-135. 
Table 1: Descriptive Statistics

\begin{tabular}{|c|c|c|c|c|c|c|c|c|}
\hline \multirow[t]{2}{*}{ Panel A. Bike use } & \multicolumn{4}{|c|}{ Trips } & \multicolumn{4}{|c|}{ Time use } \\
\hline & Mean & S.D. & Min & Max & Mean & S.D. & Min & Max \\
\hline Overall & 2791.03 & 1578.83 & 11 & 6284 & 31.82 & 6.18 & 24.09 & 53.89 \\
\hline \multicolumn{9}{|l|}{ By Age } \\
\hline$<60$ & 2706.86 & 1532.89 & 10 & 6095 & 31.55 & 6.06 & 17.4 & 53.28 \\
\hline$\geq 60$ & 84.17 & 52.08 & 1 & 225 & 39.26 & 11.54 & 20.33 & 111 \\
\hline \multicolumn{9}{|l|}{ By Gender } \\
\hline Male & 2173.84 & 1202.68 & 8 & 4643 & 30.78 & 5.7 & 24.38 & 51.24 \\
\hline Female & 617.2 & 385.1 & 3 & 1641 & 35.38 & 8.1 & 19 & 67.22 \\
\hline \multicolumn{9}{|l|}{ Panel B. Daily weather data } \\
\hline & Mean & S.D. & Min & Max & & & & \\
\hline Alert ( $=1$ if alert $)$ & 0,12 & 0,33 & 0 & 1 & & & & \\
\hline Maximum temperature $\left({ }^{0} \mathrm{C}\right)$ & 28.46 & 4.13 & 16.4 & 39 & & & & \\
\hline Rainfall ( $=1$ if rained) & 0.28 & 0.45 & 0 & 1 & & & & \\
\hline Relative humidity & 66.92 & 11.11 & 41 & 97 & & & & \\
\hline
\end{tabular}

Notes: Descriptive statistics are calculated over the sample period used in regression analysis, i.e. 373 days from October 15th to March 15th between the years of 2010 to 2014. During that period 1,041,054 trips were made. 
Table 2: Estimated Impacts of Heat Warnings on Daily Trips

\begin{tabular}{|c|c|c|c|c|c|c|}
\hline & \multicolumn{2}{|c|}{ all users } & \multicolumn{2}{|c|}{ male users } & \multicolumn{2}{|c|}{ female users } \\
\hline & $\begin{array}{c}(1) \\
\text { age }<60\end{array}$ & $\begin{array}{c}(2) \\
\text { age } \geq 60\end{array}$ & $\begin{array}{c}(3) \\
\text { age }<60 \\
\end{array}$ & $\begin{array}{c}(4) \\
\text { age } \geq 60\end{array}$ & $\begin{array}{c}(5) \\
\text { age }<60\end{array}$ & $\begin{array}{c}(6) \\
\text { age } \geq 60\end{array}$ \\
\hline \multicolumn{7}{|c|}{ Panel A. Number of trips } \\
\hline alert $_{d}$ & $\begin{array}{l}-0.0570 \\
(0.0532)\end{array}$ & $\begin{array}{c}-0.202^{* * *} \\
(0.0687)\end{array}$ & $\begin{array}{l}-0.0286 \\
(0.0532)\end{array}$ & $\begin{array}{c}-0.182^{* * *} \\
(0.0696)\end{array}$ & $\begin{array}{c}-0.166^{* * *} \\
(0.0629)\end{array}$ & $\begin{array}{c}-0.251^{* *} \\
(0.0992)\end{array}$ \\
\hline temp $\max _{d}$ & $\begin{array}{c}0.128^{* * *} \\
(0.0492)\end{array}$ & $\begin{array}{c}0.196 * * * \\
(0.0628)\end{array}$ & $\begin{array}{l}0.105^{* *} \\
(0.0467)\end{array}$ & $\begin{array}{c}0.167^{* * *} \\
(0.0602)\end{array}$ & $\begin{array}{c}0.226^{* * *} \\
(0.0690)\end{array}$ & $\begin{array}{c}0.230 * * * \\
(0.0785)\end{array}$ \\
\hline temp $\max _{d}^{2}$ & $\begin{array}{c}-0.0021^{* *} \\
(0.0009)\end{array}$ & $\begin{array}{c}-0.0032^{* * *} \\
(0.0011)\end{array}$ & $\begin{array}{c}-0.0017^{* *} \\
(0.0008)\end{array}$ & $\begin{array}{c}-0.0027^{* * *} \\
(0.0011)\end{array}$ & $\begin{array}{c}-0.0039 * * * \\
(0.0012)\end{array}$ & $\begin{array}{c}-0.0038^{* * *} \\
(0.0014)\end{array}$ \\
\hline $\operatorname{rain}_{d}$ & $\begin{array}{c}-0.230 * * * \\
(0.0418)\end{array}$ & $\begin{array}{c}-0.285^{* * *} \\
(0.0478)\end{array}$ & $\begin{array}{c}-0.207^{* * *} \\
(0.0410)\end{array}$ & $\begin{array}{c}-0.262^{* * *} \\
(0.0501)\end{array}$ & $\begin{array}{c}-0.329^{* * *} \\
(0.0501)\end{array}$ & $\begin{array}{c}-0.358^{* * *} \\
(0.0633)\end{array}$ \\
\hline $\operatorname{rain}_{d-1}$ & $\begin{array}{c}-0.1000^{* *} \\
(0.0461)\end{array}$ & $\begin{array}{l}-0.0835^{*} \\
(0.0482)\end{array}$ & $\begin{array}{c}-0.0963^{* *} \\
(0.0465)\end{array}$ & $\begin{array}{l}-0.0731 \\
(0.0478)\end{array}$ & $\begin{array}{l}-0.122^{* *} \\
(0.0519)\end{array}$ & $\begin{array}{l}-0.0709 \\
(0.0555)\end{array}$ \\
\hline humidity $_{d}$ & $\begin{array}{c}-0.012^{* * *} \\
(0.0023)\end{array}$ & $\begin{array}{c}-0.017^{* * *} \\
(0.0031)\end{array}$ & $\begin{array}{c}-0.010^{* * *} \\
(0.0022)\end{array}$ & $\begin{array}{c}-0.016 * * * \\
(0.0032)\end{array}$ & $\begin{array}{c}-0.018^{* * *} \\
(0.0030)\end{array}$ & $\begin{array}{c}-0.020^{* * *} \\
(0.0029)\end{array}$ \\
\hline constant & $\begin{array}{c}7.130^{* * *} \\
(0.692)\end{array}$ & $\begin{array}{c}3.415^{* * *} \\
(0.882)\end{array}$ & $\begin{array}{c}7.062^{* * *} \\
(0.659)\end{array}$ & $\begin{array}{c}3.507^{* * *} \\
(0.854)\end{array}$ & $\begin{array}{c}4.836^{* * *} \\
(0.953)\end{array}$ & $\begin{array}{c}1.112 \\
(1.124)\end{array}$ \\
\hline observations & 373 & 373 & 373 & 373 & 373 & 365 \\
\hline adj. r-squared & 0.922 & 0.879 & 0.924 & 0.876 & 0.895 & 0.775 \\
\hline \multicolumn{7}{|c|}{ Panel B. Trip duration } \\
\hline alert $_{d}$ & $\begin{array}{c}-0.011 \\
(0.0165)\end{array}$ & $\begin{array}{c}0.005 \\
(0.0262)\end{array}$ & $\begin{array}{c}-0.005 \\
(0.0166)\end{array}$ & $\begin{array}{c}0.025 \\
(0.0360)\end{array}$ & $\begin{array}{c}-0.021 \\
(0.0200)\end{array}$ & $\begin{array}{l}-0.086^{*} \\
(0.0485)\end{array}$ \\
\hline temp $\max _{d}$ & $\begin{array}{c}0.010 \\
(0.0120)\end{array}$ & $\begin{array}{c}0.005 \\
(0.0192)\end{array}$ & $\begin{array}{c}0.001 \\
(0.0121)\end{array}$ & $\begin{array}{c}0.002 \\
(0.0263)\end{array}$ & $\begin{array}{c}0.031^{* *} \\
(0.0147)\end{array}$ & $\begin{array}{c}0.004 \\
(0.0349)\end{array}$ \\
\hline temp $\max _{d}^{2}$ & $\begin{array}{l}-0.0001 \\
(0.0002)\end{array}$ & $\begin{array}{c}-3.32 \mathrm{e}-05 \\
(0.0003)\end{array}$ & $\begin{array}{l}9.72 \mathrm{e}-06 \\
(0.0002)\end{array}$ & $\begin{array}{l}3.24 \mathrm{e}-05 \\
(0.0005)\end{array}$ & $\begin{array}{c}-0.0005^{* *} \\
(0.0003)\end{array}$ & $\begin{array}{l}2.93 \mathrm{e}-06 \\
(0.0006)\end{array}$ \\
\hline $\operatorname{rain}_{d}$ & $\begin{array}{c}-0.028^{* * *} \\
(0.0099)\end{array}$ & $\begin{array}{c}-0.016 \\
(0.0157)\end{array}$ & $\begin{array}{l}-0.021^{* *} \\
(0.0099)\end{array}$ & $\begin{array}{c}-0.018 \\
(0.0215)\end{array}$ & $\begin{array}{c}-0.041^{* * *} \\
(0.0120)\end{array}$ & $\begin{array}{l}-0.0059 \\
(0.0285)\end{array}$ \\
\hline $\operatorname{rain}_{d-1}$ & $\begin{array}{l}-0.0106 \\
(0.0089)\end{array}$ & $\begin{array}{l}-0.0151 \\
(0.0142)\end{array}$ & $\begin{array}{l}-0.0113 \\
(0.0090)\end{array}$ & $\begin{array}{c}0.0026 \\
(0.0195)\end{array}$ & $\begin{array}{l}-0.0063 \\
(0.0109)\end{array}$ & $\begin{array}{c}-0.0761^{* * *} \\
(0.0260)\end{array}$ \\
\hline humidity $_{d}$ & $\begin{array}{c}-0.001^{* * *} \\
(0.0008)\end{array}$ & $\begin{array}{c}-0.003^{* * *} \\
(0.0008)\end{array}$ & $\begin{array}{c}-0.001 \\
(0.0005)\end{array}$ & $\begin{array}{c}-0.003 * * * \\
(0.0010)\end{array}$ & $\begin{array}{c}-0.003^{* * *} \\
(0.0006)\end{array}$ & $\begin{array}{c}-0.005^{* * *} \\
(0.0014)\end{array}$ \\
\hline constant & $\begin{array}{c}3.288^{* * *} \\
(0.175)\end{array}$ & $\begin{array}{c}3.554^{* * *} \\
(0.278)\end{array}$ & $\begin{array}{c}3.319^{* * *} \\
(0.176)\end{array}$ & $\begin{array}{c}3.544^{* * * *} \\
(0.382)\end{array}$ & $\begin{array}{c}3.208^{* * *} \\
(0.213)\end{array}$ & $\begin{array}{c}3.862^{* * *} \\
(0.505)\end{array}$ \\
\hline observations & 373 & 373 & 373 & 373 & 373 & 365 \\
\hline adj. r-squared & 0.836 & 0.797 & 0.817 & 0.701 & 0.823 & 0.584 \\
\hline
\end{tabular}

Notes: Dependent variable in Panel A is the natural logarithm of total daily trips during weekdays. Dependent variable in Panel B is the median duration of daily trips in minutes. All regressions include the following controls: month FE, month-year FE, and day of week FE. Robust standard errors in parenthesis. $*$ significant at $10 \% ; * *$ significant at $5 \% ; * * *$ significant at $1 \%$. 
Table 3: Estimated Impacts By Commuting Time

\begin{tabular}{|c|c|c|c|c|}
\hline & \multicolumn{2}{|c|}{ Morning } & \multicolumn{2}{|c|}{ Afternoon } \\
\hline & $\begin{array}{c}(1) \\
\text { age < } 60\end{array}$ & $\begin{array}{c}(2) \\
\text { age } \geq 60\end{array}$ & $\begin{array}{c}(3) \\
\text { age }<60\end{array}$ & $\begin{array}{c}(4) \\
\text { age } \geq 60\end{array}$ \\
\hline alert $_{d}$ & $\begin{array}{c}0.037 \\
(0.0823)\end{array}$ & $\begin{array}{l}-0.143 \\
(0.104)\end{array}$ & $\begin{array}{l}-0.115 \\
(0.0811)\end{array}$ & $\begin{array}{c}-0.219 * * * \\
(0.0807)\end{array}$ \\
\hline temp $\max _{d}$ & $\begin{array}{c}0.112 \\
(0.0787)\end{array}$ & $\begin{array}{c}0.239 * * * \\
(0.0886)\end{array}$ & $\begin{array}{c}0.148^{* * *} \\
(0.0510)\end{array}$ & $\begin{array}{c}0.228^{* * *} \\
(0.0685)\end{array}$ \\
\hline temp $\max _{d}^{2}$ & $\begin{array}{l}-0.0017 \\
(0.0014)\end{array}$ & $\begin{array}{c}-0.0034^{* *} \\
(0.0015)\end{array}$ & $\begin{array}{c}-0.0025^{* * *} \\
(0.0009)\end{array}$ & $\begin{array}{c}-0.004^{* * *} \\
(0.0012)\end{array}$ \\
\hline $\operatorname{rain}_{d}$ & $\begin{array}{c}-0.226^{* * *} \\
(0.0712)\end{array}$ & $\begin{array}{c}-0.233^{* * *} \\
(0.0776)\end{array}$ & $\begin{array}{c}-0.281^{* * *} \\
(0.0521)\end{array}$ & $\begin{array}{r}-0.359^{* * *} \\
(0.0629)\end{array}$ \\
\hline $\operatorname{rain}_{d-1}$ & $\begin{array}{c}-0.048 \\
(0.0647)\end{array}$ & $\begin{array}{l}-0.135^{* *} \\
(0.0640)\end{array}$ & $\begin{array}{c}-0.043 \\
(0.0355)\end{array}$ & $\begin{array}{l}-0.053 \\
(0.0501)\end{array}$ \\
\hline humidity $_{d}$ & $\begin{array}{c}-0.015^{* * *} \\
(0.0034)\end{array}$ & $\begin{array}{c}-0.017^{* * * *} \\
(0.0038)\end{array}$ & $\begin{array}{c}-0.013^{* * *} \\
(0.0045)\end{array}$ & $\begin{array}{c}-0.011^{* * * *} \\
(0.0033)\end{array}$ \\
\hline constant & $\begin{array}{c}5.201^{* * *} \\
(1.139)\end{array}$ & $\begin{array}{c}0.263 \\
(1.292)\end{array}$ & $\begin{array}{c}6.157^{* * *} \\
(0.791)\end{array}$ & $\begin{array}{l}1.653^{*} \\
(0.941)\end{array}$ \\
\hline $\begin{array}{l}\text { observations } \\
\text { adj. r-squared }\end{array}$ & $\begin{array}{c}372 \\
0.799\end{array}$ & $\begin{array}{c}354 \\
0.691\end{array}$ & $\begin{array}{c}370 \\
0.854\end{array}$ & $\begin{array}{c}365 \\
0.829\end{array}$ \\
\hline
\end{tabular}

Notes: Dependent variable is the natural logarithm of total daily trips during weekdays (all users). Morning hours are from 8am to 10am, and afternoon $4 \mathrm{pm}$ to $6 \mathrm{pm}$. All regressions include the following controls: month FE, month-year FE, and day of week FE. Robust standard errors in parenthesis. $*$ significant at $10 \%$; $*$ significant at $5 \%$;** significant at $1 \%$.

Table 4: Estimated Impacts of Warnings on Consecutive Days

\begin{tabular}{|c|c|c|c|c|c|c|}
\hline & \multicolumn{2}{|c|}{ all users } & \multicolumn{2}{|c|}{ male users } & \multicolumn{2}{|c|}{ female users } \\
\hline & $\begin{array}{c}(1) \\
\text { age }<60\end{array}$ & $\begin{array}{c}(2) \\
\text { age } \geq 60\end{array}$ & $\begin{array}{c}(3) \\
\text { age }<60\end{array}$ & $\begin{array}{c}(4) \\
\text { age } \geq 60\end{array}$ & $\begin{array}{c}(5) \\
\text { age }<60\end{array}$ & $\begin{array}{c}(6) \\
\text { age } \geq 60\end{array}$ \\
\hline alert $_{d}$ & $\begin{array}{l}-0.0899 \\
(0.0555)\end{array}$ & $\begin{array}{c}-0.221^{* * *} \\
(0.0729)\end{array}$ & $\begin{array}{l}-0.0577 \\
(0.0564)\end{array}$ & $\begin{array}{c}-0.194^{* * *} \\
(0.0720)\end{array}$ & $\begin{array}{c}-0.216^{* * *} \\
(0.0619)\end{array}$ & $\begin{array}{c}-0.282^{* * *} \\
(0.104)\end{array}$ \\
\hline $\operatorname{alert}_{d-1}$ & $\begin{array}{c}-0.0837^{*} \\
(0.0453)\end{array}$ & $\begin{array}{l}-0.0515 \\
(0.0653)\end{array}$ & $\begin{array}{l}-0.0786^{*} \\
(0.0435)\end{array}$ & $\begin{array}{l}-0.0419 \\
(0.0666)\end{array}$ & $\begin{array}{l}-0.114^{*} \\
(0.0615)\end{array}$ & $\begin{array}{c}-0.111 \\
(0.0865)\end{array}$ \\
\hline $\operatorname{alert}_{d} \times$ alert $_{t-1}$ & $\begin{array}{l}0.209^{*} \\
(0.121)\end{array}$ & $\begin{array}{c}0.117 \\
(0.140)\end{array}$ & $\begin{array}{l}0.184^{*} \\
(0.111)\end{array}$ & $\begin{array}{l}0.0749 \\
(0.149)\end{array}$ & $\begin{array}{l}0.318^{*} \\
(0.175)\end{array}$ & $\begin{array}{c}0.184 \\
(0.200)\end{array}$ \\
\hline temp $\max _{d}$ & $\begin{array}{l}0.124^{* *} \\
(0.0485)\end{array}$ & $\begin{array}{c}0.193^{* * *} \\
(0.0627)\end{array}$ & $\begin{array}{l}0.101^{* *} \\
(0.0461)\end{array}$ & $\begin{array}{c}0.165 * * * \\
(0.0600)\end{array}$ & $\begin{array}{c}0.219 * * * \\
(0.0683)\end{array}$ & $\begin{array}{c}0.223^{* * *} \\
(0.0790)\end{array}$ \\
\hline temp $\max _{d}^{2}$ & $\begin{array}{c}-0.0021^{* *} \\
(0.0009)\end{array}$ & $\begin{array}{c}-0.0032^{* * *} \\
(0.0011)\end{array}$ & $\begin{array}{c}-0.0016 * * \\
(0.0008)\end{array}$ & $\begin{array}{c}-0.0027^{* *} \\
(0.0010)\end{array}$ & $\begin{array}{c}-0.0037^{* * *} \\
(0.0012)\end{array}$ & $\begin{array}{c}-0.0036^{* *} \\
(0.0014)\end{array}$ \\
\hline $\operatorname{rain}_{d}$ & $\begin{array}{c}-0.226^{* * *} \\
(0.0416)\end{array}$ & $\begin{array}{c}-0.283^{* * *} \\
(0.0480)\end{array}$ & $\begin{array}{c}-0.203^{* * *} \\
(0.0409)\end{array}$ & $\begin{array}{c}-0.260^{* * *} \\
(0.0504)\end{array}$ & $\begin{array}{c}-0.323^{* * *} \\
(0.0497)\end{array}$ & $\begin{array}{c}-0.353^{* * *} \\
(0.0632)\end{array}$ \\
\hline $\operatorname{rain}_{d-1}$ & $\begin{array}{r}-0.103^{* *} \\
(0.0462)\end{array}$ & $\begin{array}{c}-0.0853^{*} \\
(0.0481)\end{array}$ & $\begin{array}{c}-0.0991^{* *} \\
(0.0466)\end{array}$ & $\begin{array}{c}-0.0744 \\
(0.0479)\end{array}$ & $\begin{array}{c}-0.126^{* *} \\
(0.0516)\end{array}$ & $\begin{array}{l}-0.0749 \\
(0.0553)\end{array}$ \\
\hline humidity $_{d}$ & $\begin{array}{c}-0.0118^{* * *} \\
(0.0023)\end{array}$ & $\begin{array}{c}-0.0174 * * * \\
(0.0031)\end{array}$ & $\begin{array}{c}-0.0103^{* * *} \\
(0.0023)\end{array}$ & $\begin{array}{c}-0.0160 * * * \\
(0.0033)\end{array}$ & $\begin{array}{c}-0.0182^{* * *} \\
(0.0030)\end{array}$ & $\begin{array}{c}-0.0206^{* * *} \\
(0.0029)\end{array}$ \\
\hline constant & $\begin{array}{c}7.221^{* * * *} \\
(0.683)\end{array}$ & $\begin{array}{c}3.470 * * * \\
(0.879)\end{array}$ & $\begin{array}{c}7.147^{* * * *} \\
(0.650)\end{array}$ & $\begin{array}{c}3.551^{* * *} \\
(0.848)\end{array}$ & $\begin{array}{c}4.963^{* * *} \\
(0.944)\end{array}$ & $\begin{array}{c}1.235 \\
(1.133)\end{array}$ \\
\hline observations & 372 & 372 & 372 & 372 & 372 & 364 \\
\hline adj. r-squared & 0.923 & 0.879 & 0.925 & 0.876 & 0.897 & 0.777 \\
\hline
\end{tabular}

Notes: Dependent variable is the natural logarithm of total daily trips during weekdays. All regressions include the following controls: month FE, month-year FE, and day of week FE. Robust standard errors in parenthesis. $*$ significant at $10 \%$; * significant at $5 \%$; ** significant at $1 \%$. 
Table 5: Estimated Impacts on Daily Trips Excluding Extreme Heat

\begin{tabular}{|c|c|c|c|c|c|c|}
\hline & \multicolumn{2}{|c|}{ all users } & \multicolumn{2}{|c|}{ male users } & \multicolumn{2}{|c|}{ female users } \\
\hline & $\begin{array}{c}(1) \\
\text { age }<60\end{array}$ & $\begin{array}{c}(2) \\
\text { age } \geq 60\end{array}$ & $\begin{array}{c}(3) \\
\text { age }<60\end{array}$ & $\begin{array}{c}(4) \\
\text { age } \geq 60\end{array}$ & $\begin{array}{c}(5) \\
\text { age }<60\end{array}$ & $\begin{array}{c}(6) \\
\text { age } \geq 60\end{array}$ \\
\hline \multicolumn{7}{|c|}{ Maximum Daily Temperature $<39^{\circ} \mathrm{C}$} \\
\hline alert $_{d}$ & $\begin{array}{l}-0.0629 \\
(0.0531)\end{array}$ & $\begin{array}{c}-0.204^{* * *} \\
(0.0689)\end{array}$ & $\begin{array}{l}-0.0346 \\
(0.0530)\end{array}$ & $\begin{array}{c}-0.187^{* * *} \\
(0.0697)\end{array}$ & $\begin{array}{c}-0.172^{* * *} \\
(0.0629)\end{array}$ & $\begin{array}{c}-0.248^{* *} \\
(0.0999)\end{array}$ \\
\hline obs. & 371 & 371 & 371 & 371 & 371 & 363 \\
\hline adj. r-squared & 0.923 & 0.879 & 0.925 & 0.876 & 0.896 & 0.776 \\
\hline \multicolumn{7}{|c|}{ Maximum Daily Temperature $<38^{\circ} \mathrm{C}$} \\
\hline alert $_{d}$ & $\begin{array}{c}-0.0699 \\
(0.0573)\end{array}$ & $\begin{array}{c}-0.229^{* * *} \\
(0.0705)\end{array}$ & $\begin{array}{c}-0.0388 \\
(0.0576)\end{array}$ & $\begin{array}{c}-0.206^{* * *} \\
(0.0728)\end{array}$ & $\begin{array}{c}-0.190^{* * *} \\
(0.0653)\end{array}$ & $\begin{array}{c}-0.303^{* * *} \\
(0.0935)\end{array}$ \\
\hline obs. & 369 & 369 & 369 & 369 & 369 & 361 \\
\hline adj. r-squared & 0.923 & 0.880 & 0.925 & 0.876 & 0.896 & 0.779 \\
\hline \multicolumn{7}{|c|}{ Maximum Daily Temperature $<37^{\circ} \mathrm{C}$} \\
\hline alert $_{d}$ & $\begin{array}{l}-0.0702 \\
(0.0594)\end{array}$ & $\begin{array}{c}-0.244^{* * *} \\
(0.0730)\end{array}$ & $\begin{array}{l}-0.0382 \\
(0.0597)\end{array}$ & $\begin{array}{c}-0.222^{* * *} \\
(0.0753)\end{array}$ & $\begin{array}{c}-0.194^{* * *} \\
(0.0682)\end{array}$ & $\begin{array}{c}-0.317^{* * *} \\
(0.0970)\end{array}$ \\
\hline obs. & 364 & 364 & 364 & 364 & 364 & 356 \\
\hline adj. r-squared & 0.923 & 0.880 & 0.925 & 0.876 & 0.896 & 0.779 \\
\hline \multicolumn{7}{|c|}{ Maximum Daily Temperature $<36^{\circ} \mathrm{C}$} \\
\hline alert $_{d}$ & $\begin{array}{l}-0.0735 \\
(0.0586)\end{array}$ & $\begin{array}{c}-0.245^{* * *} \\
(0.0724)\end{array}$ & $\begin{array}{l}-0.0414 \\
(0.0591)\end{array}$ & $\begin{array}{c}-0.223^{* * *} \\
(0.0747)\end{array}$ & $\begin{array}{c}-0.198^{* * *} \\
(0.0667)\end{array}$ & $\begin{array}{c}-0.313^{* * *} \\
(0.0957)\end{array}$ \\
\hline obs. & 361 & 361 & 361 & 361 & 361 & 353 \\
\hline adj. r-squared & 0.925 & 0.881 & 0.927 & 0.878 & 0.898 & 0.782 \\
\hline \multicolumn{7}{|c|}{ Maximum Daily Temperature $<35^{\circ} \mathrm{C}$} \\
\hline alert $_{d}$ & $\begin{array}{l}-0.0587 \\
(0.0553)\end{array}$ & $\begin{array}{c}-0.207^{* * *} \\
(0.0685)\end{array}$ & $\begin{array}{c}-0.0306 \\
(0.0552)\end{array}$ & $\begin{array}{c}-0.188^{* *} \\
(0.0734)\end{array}$ & $\begin{array}{c}-0.170^{* *} \\
(0.0660)\end{array}$ & $\begin{array}{c}-0.286^{* * *} \\
(0.0975)\end{array}$ \\
\hline observations & 350 & 350 & 350 & 350 & 350 & 345 \\
\hline adj. r-squared & 0.922 & 0.872 & 0.924 & 0.868 & 0.892 & 0.779 \\
\hline
\end{tabular}

Notes: Dependent variable is the natural logarithm of total daily trips during weekdays. All regressions include the following controls: linear and quadratic daily maximum temperature, relative humidity, dummy variables for rainfall in $d$ and $d-1$, month $\mathrm{FE}$, month-year $\mathrm{FE}$, and day of week FE. Robust standard errors in parenthesis. * significant at $10 \%$; ${ }^{*}$ significant at $5 \% ; * * *$ significant at $1 \%$. 
Table 6: Modeling Temperature By Piecewise Polynomial Functions

\begin{tabular}{|c|c|c|c|c|c|c|}
\hline & \multicolumn{2}{|c|}{ all users } & \multicolumn{2}{|c|}{ male users } & \multicolumn{2}{|c|}{ female users } \\
\hline & $(1)$ & $(2)$ & $(3)$ & $(4)$ & $(5)$ & $(6)$ \\
\hline & age $<60$ & age $\geq 60$ & age $<60$ & age $\geq 60$ & age $<60$ & age $\geq 60$ \\
\hline \multicolumn{7}{|c|}{ Panel A. Number of trips } \\
\hline \multirow[t]{2}{*}{ alert $_{d}$} & -0.0308 & $-0.168^{* * *}$ & -0.00236 & $-0.149^{* *}$ & $-0.141 * *$ & $-0.227^{* *}$ \\
\hline & $(0.0533)$ & $(0.0641)$ & $(0.0538)$ & $(0.0654)$ & $(0.0618)$ & $(0.101)$ \\
\hline \multirow[t]{2}{*}{$\operatorname{rain}_{d}$} & $-0.227 * * *$ & $-0.281 * * *$ & $-0.203^{* * *}$ & $-0.258 * * *$ & $-0.328 * * *$ & $-0.357 * * *$ \\
\hline & $(0.0408)$ & $(0.0476)$ & $(0.0398)$ & $(0.0495)$ & $(0.0501)$ & $(0.0634)$ \\
\hline \multirow[t]{2}{*}{$\operatorname{rain}_{d-1}$} & $-0.101^{* *}$ & $-0.0850^{*}$ & $-0.0978^{* *}$ & -0.0746 & $-0.123^{* *}$ & -0.0717 \\
\hline & $(0.0463)$ & $(0.0483)$ & $(0.0467)$ & $(0.0479)$ & $(0.0519)$ & $(0.0556)$ \\
\hline humidity $_{d}$ & $\begin{array}{c}-0.0120^{* * *} \\
(0.0024)\end{array}$ & $\begin{array}{c}-0.0178^{* * *} \\
(0.0031)\end{array}$ & $\begin{array}{c}-0.0106 * * * \\
(0.0023)\end{array}$ & $\begin{array}{c}-0.0165 * * * \\
(0.0033)\end{array}$ & $\begin{array}{c}-0.0181^{* * *} \\
(0.0030)\end{array}$ & $\begin{array}{c}-0.0207 * * * \\
(0.0029)\end{array}$ \\
\hline \multirow{2}{*}{ constant } & $8.640^{* * *}$ & $5.453^{* * *}$ & $8.411^{* * *}$ & $5.357^{* * *}$ & $6.940^{* * *}$ & $3.194^{* * *}$ \\
\hline & $(0.585)$ & $(0.693)$ & $(0.564)$ & $(0.681)$ & $(0.785)$ & $(0.741)$ \\
\hline observations & 372 & 372 & 372 & 372 & 372 & 364 \\
\hline r-squared & 0.923 & 0.881 & 0.925 & 0.877 & 0.896 & 0.776 \\
\hline \multicolumn{7}{|c|}{ Panel B. Trip duration } \\
\hline \multirow[t]{2}{*}{ alert $_{d}$} & -0.0066 & 0.0041 & -0.0010 & 0.0245 & -0.0137 & -0.0776 \\
\hline & $(0.0169)$ & $(0.0270)$ & $(0.0171)$ & $(0.0371)$ & $(0.0206)$ & $(0.0500)$ \\
\hline \multirow[t]{2}{*}{$\operatorname{rain}_{d}$} & $-0.0265^{* * *}$ & -0.0155 & $-0.0202^{* *}$ & -0.0180 & $-0.0403^{* * *}$ & -0.0042 \\
\hline & $(0.00987)$ & $(0.0157)$ & $(0.00996)$ & $(0.0216)$ & $(0.0120)$ & $(0.0286)$ \\
\hline \multirow[t]{2}{*}{$\operatorname{rain}_{d-1}$} & -0.0109 & -0.0154 & -0.0116 & 0.0023 & -0.0067 & $-0.0765 * * *$ \\
\hline & $(0.00893)$ & $(0.0142)$ & $(0.00901)$ & $(0.0196)$ & (0.0109) & $(0.0260)$ \\
\hline \multirow[t]{2}{*}{ humidity $_{d}$} & $-0.0014^{* * *}$ & $-0.0028^{* * *}$ & -0.0008 & $-0.0028^{* * *}$ & $-0.0028^{* * *}$ & $-0.0050 * * *$ \\
\hline & $(0.0005)$ & $(0.0008)$ & $(0.0005)$ & $(0.0011)$ & $(0.0006)$ & $(0.0014)$ \\
\hline \multirow[t]{2}{*}{ constant } & $3.482^{* * *}$ & $3.630 * * *$ & $3.431^{* * *}$ & $3.624^{* * *}$ & $3.599^{* * *}$ & $4.064 * * *$ \\
\hline & $(0.127)$ & $(0.202)$ & $(0.128)$ & $(0.278)$ & $(0.154)$ & $(0.366)$ \\
\hline observations & 372 & 372 & 372 & 372 & 372 & 364 \\
\hline adj. r-squared & 0.837 & 0.798 & 0.817 & 0.701 & 0.825 & 0.586 \\
\hline
\end{tabular}

Notes: Dependent variable in Panel A is the natural logarithm of total daily trips during weekdays. Dependent variable in Panel B is the median duration of daily trips in minutes. All regressions include the following controls: five splines for daily maximum temperature, month FE, month-year FE, and day of week FE. Robust standard errors in parenthesis. ${ }^{*}$ significant at $10 \%$; ${ }^{* *}$ significant at $5 \%$; $* * *$ significant at $1 \%$. 
Table 7: Falsification Tests

\begin{tabular}{|c|c|c|c|c|c|c|}
\hline & \multicolumn{2}{|c|}{ all users } & \multicolumn{2}{|c|}{ male users } & \multicolumn{2}{|c|}{ female users } \\
\hline & $(1)$ & $(2)$ & $(3)$ & $(4)$ & $(5)$ & $(6)$ \\
\hline & age $<60$ & age $\geq 60$ & age $<60$ & age $\geq 60$ & age $<60$ & age $\geq 60$ \\
\hline \multicolumn{7}{|c|}{ Panel A. Number of trips } \\
\hline \multirow[t]{2}{*}{ alert $_{t}$} & 0.0292 & -0.0208 & 0.0413 & 0.0238 & -0.0306 & -0.0385 \\
\hline & $(0.0656)$ & $(0.0894)$ & $(0.0629)$ & $(0.0902)$ & $(0.0952)$ & $(0.0769)$ \\
\hline \multirow{2}{*}{ temp $\max _{d}$} & $0.145^{* * *}$ & $0.253^{* * *}$ & $0.114^{* * *}$ & $0.220^{* * *}$ & $0.273^{* * *}$ & $0.300^{* * *}$ \\
\hline & $(0.0467)$ & $(0.0614)$ & $(0.0440)$ & $(0.0589)$ & $(0.0667)$ & $(0.0687)$ \\
\hline \multirow[t]{2}{*}{ temp $\max _{d}^{2}$} & $-0.0025^{* * *}$ & $-0.0044^{* * *}$ & $-0.0019 * *$ & $-0.0038 * * *$ & $-0.0048 * * *$ & $-0.0052^{* * *}$ \\
\hline & $(0.0008)$ & $(0.0011)$ & $(0.0008)$ & $(0.0010)$ & $(0.0011)$ & $(0.0012)$ \\
\hline \multirow[t]{2}{*}{$\operatorname{rain}_{t}$} & $-0.227 * * *$ & $-0.276^{* * *}$ & $-0.205^{* * *}$ & $-0.253^{* * *}$ & $-0.321^{* * *}$ & $-0.349 * * *$ \\
\hline & $(0.0415)$ & $(0.0481)$ & $(0.0406)$ & $(0.0499)$ & $(0.0502)$ & $(0.0640)$ \\
\hline \multirow[t]{2}{*}{$\operatorname{rain}_{t-1}$} & $-0.0984^{* *}$ & -0.0801 & $-0.0951^{* *}$ & -0.0693 & $-0.119 * *$ & -0.0650 \\
\hline & $(0.0461)$ & $(0.0487)$ & $(0.0464)$ & $(0.0482)$ & $(0.0524)$ & $(0.0559)$ \\
\hline \multirow[t]{2}{*}{ humidity $t$} & $-0.0113^{* * *}$ & $-0.0170 * * *$ & $-0.0099 * * *$ & $-0.0155^{* * *}$ & $-0.0176^{* * *}$ & $-0.0199 * * *$ \\
\hline & $(0.0024)$ & $(0.0032)$ & $(0.0023)$ & $(0.0033)$ & $(0.0031)$ & $(0.0029)$ \\
\hline \multirow[t]{2}{*}{ constant } & $6.892^{* * *}$ & $2.670^{* * *}$ & $6.922^{* * *}$ & $2.802^{* * *}$ & $4.235^{* * *}$ & 0.204 \\
\hline & $(0.645)$ & $(0.839)$ & $(0.608)$ & $(0.812)$ & $(0.905)$ & $(1.006)$ \\
\hline observations & 372 & 372 & 372 & 372 & 372 & 364 \\
\hline adj. r-squared & 0.922 & 0.877 & 0.924 & 0.874 & 0.894 & 0.771 \\
\hline
\end{tabular}

Notes: Dependent variable is the natural logarithm of total daily trips during weekdays. All regressions include the following controls: five splines for daily maximum temperature, month FE, month-year FE, and day of week FE. Robust standard errors in parenthesis. * significant at $10 \%$; ** significant at $5 \%$; *** significant at $1 \%$. 

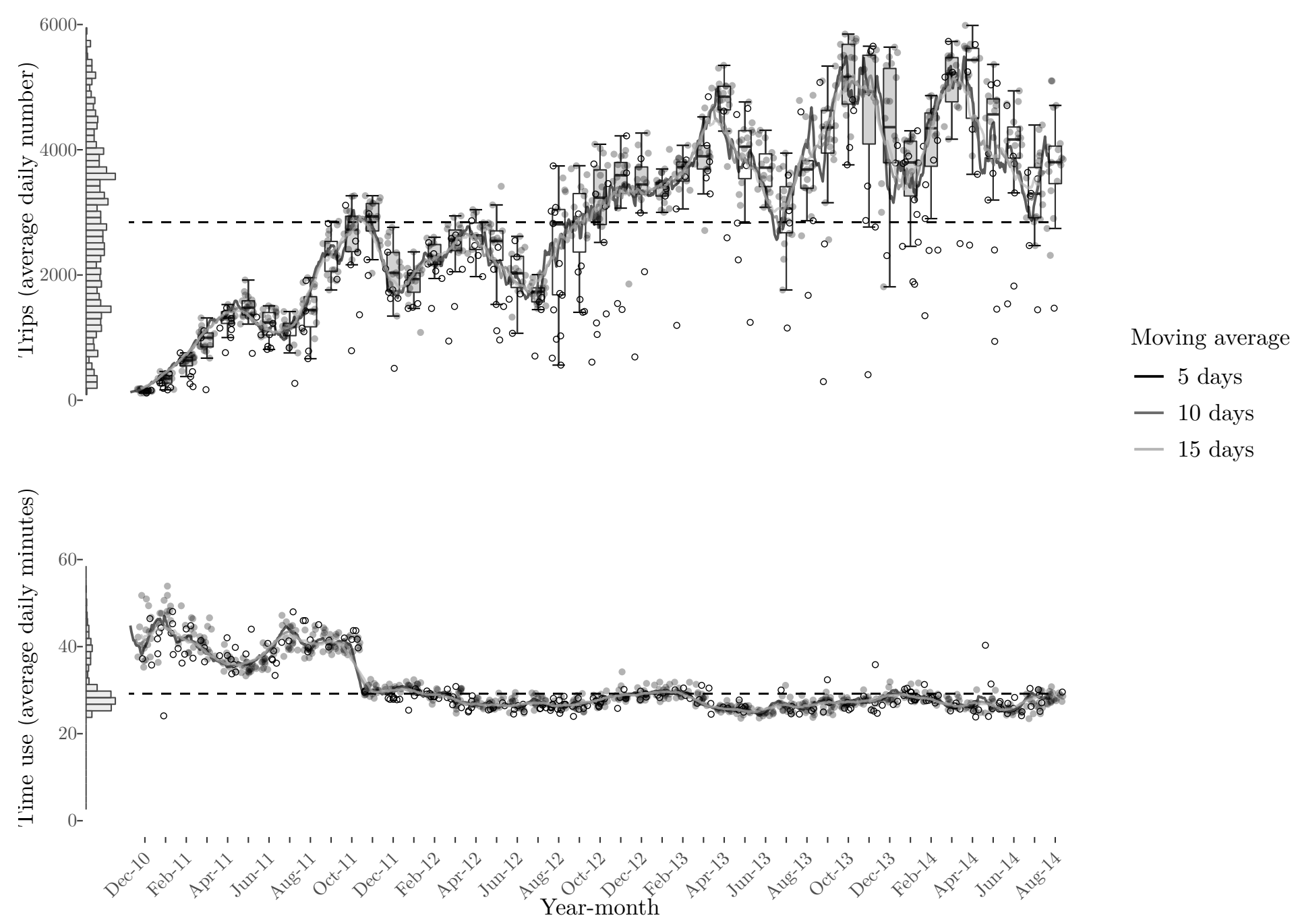

Notes: Panel A shows the number of trips made using EcoBici between 2010 and 2014. Each point shows the daily count of trips, with hollow circles representing rainy days and filled circles days with no rain. Each box plot measures usage dispersion within any given month. Panel B shows average daily trip duration in minutes. Solid lines correspond to movings averages over the entire period. 